\title{
Neue Experimente zur Function des Corpus luteum.
}

\author{
Von
}

\section{Fraenkel.}

Vor 7 Jahren habe ich (1) die "Function des Corpus luteum" in diesem Archiv veröffentlicht und Ende desselben Jahres in der Wiener gynäkologischen Gesellschaft weitere Mittheilungen über das Thema gebracht. Im Anschluss hieran wurde eine eingehende Discussion geführt. Die dort vorgebrachten Einwände glaube ich Punkt für Punkt in einem ausführlichen Schlusswort als nicht stichbaltig erwiesen zu haben mit Ausnahme eines einzigen, der von Halban (2) gemacht wurde. Er bezeichnete die damalige Zahl der Experimente als zu klein, um eine so wichtige Theorie daraus abzuleiten. Ich hatte Versuche an 120 Thieren gemacht, die sich auf verschiedene Experimentalreihen so vertheilten, dass innerhalb jeder Serie die Zahl naturgemäss wesentlich kleiner sein musste. Indessen schienen mir die innerhalb von 4 Jahren angestellten Versuche eine so deutliche Sprache zu reden und Zufälligkeiten auszuschliessen, dass ich die Zahlen für genügend gross ansah. Nachdem sie für nicht ausreichend erklärt wurden, war es nothwendig, die Experimente, die mir in der Hauptsache abgeschlossen erschienen, fortzuführen. Das habe ich am Ende des Schlusswortes versprochen. Diese Zusage will ich heute einlösen, indem ich das Ergebniss von 277 neuen Versuchen mittheile.

Auf der Naturforscherversammlung des Jahres 1904 bin ich auf die ersten 59 dieser Versuche eingegangen, weil ich mit ihnen ein zweites von Schauta (3) gestelltes Postulat erfüllen konnte, nämlich nachzuweisen, dass die Ovarien, an denen ich experimentell die gelben Körper entfernt hatte, zur weiteren Fortpflanzung geeignet sind; doch habe ich diese Fälle und meine damaligen Ausführungen nicht publicirt, weil ich bis zur definitiven Fertigstellung 
aller geforderten Experimente warten wollte. Ich unterbreite im Folgenden mein seit 1904 gesammeltes Material.

Die von mir unter Beweis gestellte crste Behauptung lautet: Der gelbe Körper ist eine Drüse mit innerer Secretion. Sie bewirkt diejenigen Veränderungen, welche dem Ei die Ansiedlung im Fruchthalter ermöglichen.

Zur Untersuchung der "Function des Corpus luteum" habe ich die Ausschaltung des gelben Körpers vorgenommen. Es handelt sich teils um die negative Beweisführung: Ausbleiben der Gravidität bei Wegfall des Corpus luteum, teils um die positive: Belassen von Luteingewebe. - Ungestörte Gravidität. Die Eorderung ist berechtigt, dass die Zahl der beweisenden Fälle möglichst gross sei, beziehungsweise im Einklang stehe mit Controllfällen von entgegengesetztem Ausgang. Alle Versuche wurden mit Lepus euniculus vorgenommen, dessen wichtigste sexualphysiologische Daten ich hier wiederhole: Das Kaninchen trägt vom befruchtenden Coitus an 28-31 Tage. (Die Schwankung um 3 Tage erklärt manche scheinbaren Widersprüche zwischen der Tragzeit und Eigrösse; in der ungünstigen Jahreszeit scheinen die Eier langsamer zu. wachsen.) Die Eier werden auf dem Ovarium oder im lateralen Drittel der Tube meist sogleich nach dem Coitus, sonst im Laufe der nächsten 1-2 Tage befruchtet, gelangen am 3. Tage nach der Imprägnation in den Uterus und am 6.-9., fast immer am Beginn vom 7., Tage in ihm zur Anheftung; daselbst bewirken sie innerhalb weniger Stunden von aussen sichtbare, erbsengrosse, röthlich-glasige Anschwellungen.

\section{Die Versuchsprotokolle}

schliessen sich an diejenigen der ersten Arbeit an und bedürfen daher nur weniger erläuternder Worte: Es wurden ausgeführt:

$\begin{array}{ccccc}\text { Im Jahre } & 1904 & 59 & \text { Experim } \\ " & n & 1905 & 11 & n \\ " & n & 1906 & 41 & n \\ " & n & 1907 & 45 & n \\ " & n & 1908 & 32 & n \\ " & n & 1909 & 51 & " \\ " & n & 1910 & 38 & n\end{array}$

deren Bezeichnung "hronologisch nach den Jahrgängen läuft. Ich gebe kurze Auszüge aus den Protokollen aller derjenigen Versuche, welche für die Corpus luteum-Frage in Betracht kommen, über 
L. Fraenkel, Neue Experimente zur Function des Corpus lnteum. 707

die anderen Beobachtungen nur eine Gesammtübersicht. Die Aufführung der Einzelexperimente habe ich nach den Hauptfragestellungen gesichtet:

1. Castrationen,

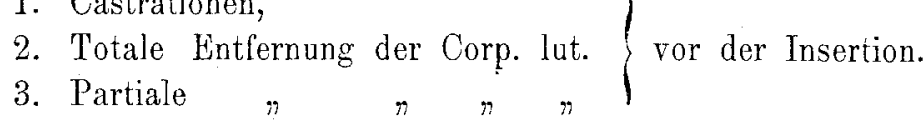

4. Castrationen.

5. Totale Entfernung der Corp. lut. $\{$ nach der Insertion.

7. Neue Conception nach Igniexcision der Corp. lut.

8. Nur Narkose, nur Laparotomie, Brandschorfe neben dic Corp. lut.

9. Die Fälle, die nach dem 14. Tag operirt sind.

Controlen.

Die Operationen waren alle vollkommen gleichartig angeordnet. Die Narkose, wie früher mit Morphium und Chloralhydrat, ergab nur wenige Versager, die wohl mit Fehlern der Injectionstechnik oder Dosirung zusammenhingen. Einziges Desinficiens der Hände und Bauchhaut: Seifenspiritus. Ligatur, Nähmaterial: feinster Zwirn. Die Asepsis functionirte durchgehend tadellos. Wo nichts besonderes vermerkt ist, stimmte die Grösse der Eikammern mit dem Belegungstage überein, erfolgte glatte Reconvalescenz, wurde das Thier bei vollkommenem Wohlbefinden durch Nackenschlag getödtet, ergab die Section ${ }^{1}$ ) prima intentio bei spiegelnder, adhäsionsloser Bauchhöhle. Die Genitalien wurden genau beschrieben, conservirt, in vielen Fällen mikroskopisch untersucht.

Bei der Anstellung der Versuche, der Sectionen, Untersuchungen wurde ich wie früher von L. Conrat aufs Wirksamste unterstützt.

\section{Castrationen vor der Ei-Insertion.}

No. 56, 1904. Am 30. 7. belegt. 4. 8. Castration: Rechts 3, links 2 Corp. Jut. 19. 8. Section: Keine Gravidität.

No. 58, 1904. Am 24. 8. belegt. 27. 8. Cástration: Rechts 2, links 1 Corp. lut. 7. 9. Section: Keine Gravidität.

1) Anm. Die Section wurde im Allgemeinen nacb 5 Tagen vorgenommen. Die trockene Rückbildung der Eier, wie ich früher gezeigt habe, der häufigste Modus der Schwangerschaftsunterbrechung bei Kaninchen, wurde zu dieser Zeit in ganz verschiedenen Stärkegraden gefunden. Bilder mit noch erkennbarem Foetus und kaum verkleinerter Eikammer wechselten mit totaler Uterusinvolution und allen $Z$ wischenstufen ab, ohne dass es bisher gelang, die Gründe für dieses differirende Verhalten aufzufinden. 
No. 59, 1904. Am 24. 8. belegt. 27. 8. Castration: Rechts 3, links 1 Corp. lut. Wurf erfogt nicht. 27. 9. Section: Castrationsatrophie.

No. 1, 1905. Am 5. 5. belegt. 8. 5. Castration: Je 3 Corp. lut auf den Ovarien. Geburt erfolgt nicht. 9. 6. Section: Uterus leer.

No. 3, 1908. Am 16. 5. belegt. 22. 5. Castration: Rechts reichlich, links 2 Corp. lut. 29. o. Section: Keine Gravidität.

No. 4, 1908. Am 17. 5. belegt. 22. 5. Castration: Reichlich Corp. Int. auf beiden Ovarien. 29. 5. Section: Keine Gravidität.

No. 6, 1908. Am 27. 5. belegt. 29. 5. Castration: Je 5 Corp. lut. 4. 6. Section: Keine Gravidität.

No. 7, 1908. Am 10. 6. belegt. 14. 6. Castration: Reichlich Corp. lut. auf beiden Ovarien. 22. 6. Section: Keine Gravidität.

No. 8, 1908. Am 8. 6. belegt. 14. 6. Castration: Reichlich Corp. Iut. auf beiden Ovarien. 22. 6. Section: Keine Gravidität.

No. 30, 1908. Am 20. 10. belegt. 25. 10. Castration: Rechts 2, links 6 Corp. lut. 30. 10. Section: Keine Gravidität.

\section{Totalentfernung der Corp. lut. vor der Ei-Insertion.}

No. 49, 1904: Am 21. 6. belegt. 23. 6. rechts 7, links 0 Corp. lut. ausgebrannt. 9. 7. Section: Keine Gravidität, keine Corp. lut.

No. 10, 1905. Am 1. 7. belegt. 9. 7. links 4, rechts 1 Corp. lut. ausgebrannt. 20. 7. von neuem belegt. 29. 7. zweite Laparotomie: Keine Gravidität, frische Ovulation.

No. 11, 1905. Am 13. 7. belegt. 21. 7. rechts 3, Corp. lut. ausgebrannt. 12. 8. Section: Keine Graviditä, keine Corp. lut.

ํo. 14, 1906. Am 20. 4. belegt. 25. 4. je う Corp. lut. ausgebrannt: 4. 5. Section: Keine Gravidität, keine Corp. lut.

No. 15, 1906, Am 18. 4. belegt. 24. 4. rechts 4, links ó Corp. lut. ausgebrannt. 4. 5. Section: Keine Gravidität, keine Corp. Iut.

No. 20, 1906. Am 19. 5. belegt. 25. 5. rechts 3, links 5 Corp. lut. ausgebrannt. 31. 5. Section: Keine Gravidität, keine Corp. Lut.

No. 23, 1906. Am 21. 5. belegt. 27. 5. rechts 4, links 3 Corp. Iut. ausgebrannt. 31. 5. Section: Keine Gravidität, keine Corp. lut.

No. 27, 1906. Am 20. 6. belegt. 26. 6. rechts 3, links 4 Corp. lut. ausgebrannt. 3. 7. Section; Keine Gravidität, keine Corp. lut.

No. 29, 1906. Am 22. 6. belegt. 28. 6. rechts 2, links 7 Corp. Iut. ausgebrannt. 3. 7. Section: Keine Gravidität, keine Corp. Iut.

No. 30, 1906. Am 24. 6. belegt. 28. 6. je 3 Corp. lut. ausgebrannt. 5. 7. Section: Keine Graviditä, keine Corp. lut.

No. 31, 1906. Am 29. 6. belegt. 4. 7. links 4, rechts 3 Corpus lut. ausgebrannt. 9. 7. Section: Keine Gravidität. keine Corp. lut.

No. 32, 1906. Am 4. 7. belegt. 10. 7. rechts 3, links 5 Corp. lut. ausgebrannt. 15. 7. Section: Keine Graviditat, keine Corp. lut.

No. 33, 1906. Am 16. 7. belegt. 22. 7. rechts 9, links 2 Corp. lut. ausgebranut. 27. 7. Section: Keine Gravidität, keine Corp. Lut.

No. 35, 1906. Am 17. 7. belegt. 22. 7. rechts 7, links 6 Corp. lut. ausgebrannt. 27. 7. Section: Keine Gravidität, keine Corp. Jut.

No. 36, 1906. Am 17. 7. belegt. 22. 7. rechtes Ovarium ohne Corp. lut.; links 9 Corp. lut. ausrebrannt. 27. 7. Section: Keine Gravidität, keine Corp. lut.

No. 37, 1906. Am 23. 7. belegt. 29. 7. rechts 7, links 5 Corp. lut. ausgebrannt. 4. 8. Section: Keine Gravidität, keine Corp. Iut. 
No. 40, 1906. Am 19. 9. belegt. 25. 9. rechts 5, links 4 Corp. lut. ausgebrannt. 30. 9. Section: Keine Gravidität, keine Corp. lut.

Yo. 41, 1906. 21. 9. belegt. 24. 9. rechts 5, links 5 Corp. lut. ausgebrannt. 30. 9. Section: Keine Gravidität, keine Corp. lut.

No. 5, 1907. Am 7. 4. belegt. 12. 4. rechts 4, links $2-3$ Corp. lut. ausgebrannt. 16. 4. Section: Keine Gravidität, keine Corp. lut.

No. 7, 1907. Am 11. 4. belegt. 17. 4. je 4-5 Corp. Iut. ausgebrannt. 23. 4. Section: Keine Gravidität, keine Corp. lut.

No. 8, 1907. Am 13. 4. belegt. 1\%. 4. je 2-3 Corp. lut. ausgebrannt. 23. 4. Section: Keine Gravidität, keine Corp. lut.

No. 10, 1907. Am 21. 4. belegt. 25. 4. je 4-5 Corp. lut. ausgebrannt. Todt am 29. 4. Section: Lungentuberculose, keine Gravidität, keine Corp. lut.

No. 15, 1907. Am 28. 5. belegt. 4. 5. rechts 2, links 4 Corp. lut. ausgebrannt. 12. 5. Section: Keine Gravidität. Linkes Ovarium luteopriv. Rechtes makroskopisch scheinbar ein Corp. lut.; mikroskopisch: Corpus albicans.

No. 17, 1907. Am 5. 5. belegt. 11. 5. links 4 Corp. lut. ausgebrannt. 18. 5. Section: Keine Gravidität, kein Corp. lut.

No. 18, 1907. Am 7. 5. belegt. 11. 5. rechts 3, links 4 Corp. lut. ausgebrannt. 18. 5. Section: Keine Gravidität, keine Corp. lut.

No. 20, 1907. Am 16. 5. belegt. 21. 5. je 4-6 Corp. Int. ausgebrannt. 27. 5. Section: Keine Gravidität, keine Corp. lut.

No. 23, 1907. Am 1. 6. belegt. 6. 6. rechts $6-7$, links $4-5$ Corp. lut. ausgebrannt. 13. 6. Section: Keine Gravidität, keine Corp. lut.

No. 27, 1907. Am 9. 6. belegt. 14. 6. rechts 1, links 4 Corp. Iut. ausgebrannt. 20. 6. Section: Keine Gravidität, keine Corp. lut.

No. 29, 1907. Am 16. 6. belegt. 23. 6. je 2-3 Corp. lut. ausgebrannt. 1. 7. Section: Keine Gravidität, keine Corp. lut.

No. 30, 1907. Am 18. 6. belegt. 23. 6. je 3-4 Corp. lut. ausgebrannt. 1. 7. Section: Keine Gravidität, keine Corp. lut. Links wird eine auf Corp. lut. verdächtige Stelle mikroskopirt und ein Corp. albicans constatirt.

No. 31, 1907. Am 23. 6. belegt. 28. 6. rechts 5, links 3 Corp. lut. ausgebrannt. 1. 7. Section: Keine Gravidität, keine Corp. lut.

No. 34, 1907. Am 29. 6. belegt. 3. 7. beiderseits reichliche Corp. lut. ausgebrannt. 12. 7. Section: Keine Gravidität, keine Corp. lut.

No. 35, 1907. Am 14. 7. belegt. 19. 7. je 2-3 Corp. lut. ausgebrannt. 29. 7. Section: Keine Gravidität, keine Corp. lut.

No. 37, 1907. Am 21. 7. belegt. 25. 7. auf beiden Ovarien reichliche Corp. lut. ausgebrannt. 29. 7. Section: Keine Gravidität, Keine Corp. lut.

No. 41, 1907. Am 9. 9. belegt. 15. 9. rechts 2, links $6-7$ Corp. lut. ausgebrannt. 19. 9. Section: Keine Gravidität, keine Corp. lut.

No. 1, 1908. Am 27. 4. belegt. 3. 5. je 4-5 Corp. lut. ausgrebrannt. 10. 5. Section: Keine Gravidität, keine Corp. Iut.

No. 2, 1908. Am 2. 5. belegt. 7. 5. je 4 Corp. lut. ausgebrannt. 10. 5. Section: Keine Gravidität, keine Corp. lut.

No. 5, 1908. Am 19. 5. belegt. 22. 5. rechts 2, links 5 Corp. lut. stumpf enthülst. 29. 5. Section: Keine Graviditat, keine Corp. lut.

No. 9, 1908. Am 22. 6. belegt. 28. 6. rechts 5, links 2 Corp. Iut. ausgebrannt. 6. 7. Section: Keine Gravidität, keine Corp. lut. 
No. 15, 1908. Am 17. 7. belegt. 22. 7. je 3-4 Corp. lut. ausgebrannt. 30. 7. Section: Keine Gravidität, keine Corp. Iut.

No. 16, 1908. Am 19. 7. belegt. 22. 7. je 4 Corp. lut. ausgebrannt. 30. 7. Section: Keine Gravidität, keine Corp. lut.

No. 21, 1908. Am 26. 7. belegt. 1. 8. rechts 5, links 2 Corp. lut. stumpf enthülst. 8. 8. Section: Keine Gravidität, keine Corp. lut.

No. 23, 1908. Am 6. 8. belegt. 12. 8. rechts 3, links 5 Corp. lut. stumpf enthülst. 16. 8. Section: Keine Gravidität, keine Corp. lut.

No. 27, 1908. Am 31. 8. belegt. 4. 9. jederseits reichliche Corp. lut. ausgebrannt. 9. 9. Section: Keine Gravidität, keine Corp. lut.

No. 28, 1908. Am 1. 9. belegt. 4. 9. rechts 4-5. links 3 Corp. lut. ausgebrannt. 9. 9. Section: Keine Gravidität, keine Corp. lut.

No. 29, 1908. Am 13. 10. belegt. 18. 10. je 4 Corp. lut. ausgebrannt. 23. 10. Section: Keine Gravidität, keine Corp. lut.

Fo. 41, 1909. Am 7. 7. belegt. 11. 7. rechts 4-5, links 2 Corp. lut. stumpf enthülst. 16. 7. Section: Keine Gravidität, keine Corp. lut.

No. 44, 1909. Am 9. 7. belegt. 14. 7. rechts 3 , links $4-5$ Corp. Jut. stumpf enthülst. 19. 7. Section: Keine Gravidität. Linkes Ovarium luteopriv; rechtes makroskopisch zweifelhaft; mikroskopisch: Schöne glande und viele heranwachsende Follikel. Keinerlei Luteingewebe.

\section{Partielle Entfernung der Corp. lut. vor der Ei-Insertion.}

No. 51, 1904. Am 1. 7. belegt. 6. 7. rechts 2, links 2 Corp. lut. ausgebrannt (von je 4). 10.7. Section: Jederseits 4 Kammern vom vom 10. Tag und je 2 unberührte Corp. Iut.

No. 53, 1904. Am 13. 7. belegt. 15. 7. rechts 2. links 1 Corp. lnt. ausgebrannt. 24. 7. Section: Linkes Horn leer, rechts 8 Kammern vom 11. Tag. Rechtes Ovarium enthält 2, linkes 3 unberührte Corp. lut.

No. 21, 1906. Am 21. 5. belegt. 27. 5. rechts 4, links 5 Corp. lut. ausgebrannt. 31. 5. Section: Keine Gravidität. Am linken Ovarium ein unberührtes Corp. lut.

No. 22, 1906. Am 20. 5. belegt. 27. 5. rechts 3, links 5 Corp. lut. ausgebrannt. 31. 5. Section: Rechts 3, links 2 Kammern vom 11. Tag. Bei erster Betrachtung scheint kein Luteingewebe vorhanden zu sein. Die genaue Untersuchung aber ergiebt im rechten sowie linken Ovarium je ein unberührtes Corpus luteum. (Mikroskopisch bestätigt).

No. 39, 1906. Am 13. 9. belegt. 18. 9. rechts 1, links 2 Corp. lut. ausgebrannt. 23. 9. Keine Gravidität; links ein unberührtes Corp. lut.

No. 1, 1907. Am 20. 1. belegt. 25. 1. Rechtes Ovarium mit 3 Corp. lut. exstirpirt; links 6 Corp. lut. ausgebrannt. 30. 1. Section: Keine Gravidität. Linkes Ovarium enthält einige Corp. lut.

No. 9, 1907. Am 12. 5. belegt. 17. 5. rechts 4, links 2 Corp. lut. ausgebrannt. 27. 5. Section: Keine Gravidität; links 1 Corp. lut., mikroskopișch bestätigt.

No. 16, 1907. Am 30. 4. belegt. 4. 5. je 2 Corp. lut. ausgebrannt. 12. 5. Section: Je 1 Kammer vom 13. Tag. Im linken Ovarium 1, im rechten 2 unberührte Corp. lut.

No. 19, 1907. Am 9. 5. belegt. 14.5. je drei Corp. lut. ausgebrannt. 
18. 5. Section: Keine Gravidität; rechts ein unberührtes, frisches Corp. lut. mikroskopisch bestätigt.

No. 21, 1907. Am 26. 5. belegt. 30. 5. rechts 2, links 3 Corp. lut. ausgebrannt. 6. 6. Section: rechts 6 Kammern vom 11. Tag; links die Kammern im Rückgang. Im rechten Ovarium 3 unberührte Corp. lut., von denen eins polypös gestielt räumlich vom übrigen Ovarium getrennt liegt. Links ein grosses Corpus lut. (mikroskopisch verificirt).

No. 22, 1907. Am 25. 5. belegt. 30. 5. rechts 2, links 1 Corp. lut. ausgebrannt. 6. 5. Keine Gravidität. Im linken Ovarium ein unberührtes Corp. lut., mikroskopisch bestätigt.

No. 26, 1907. Am 8. 6. belegt. 14. 6. rechts 4, links 1 Corp. lut. ausgebrannt. 20. 6. Section: Keine Gravidität; ein unberührtes Corp. lut. im linken Ovarium (mikroskopisch verificirt).

No. 30, 1907. Am 18. 6. belegt. 23. 6. je 3 Corp. lut. ausgebrannt. 1. 7. Section: Keine Gravidität; rechts 1 unberührtes Corp. lut., links ein kleines Corp. albicans (mikroskopisch bestätigt).

No. 33, 1907. Am 23. 6. belegt. 26. 6. rechts 4 . links 5 Corp. lut. ausgebrannt. 1. 7. Section: rechts 3, links 6 Kammern vom 8. Tag. Einige unberührte Corp. lut. neben den Schorfen.

No. 39, 1907. Am 8. 9. belegt. 12. 9. je 3 Corp. lut. ausgebrannt. 19. 9. Section: Keine Gravidität; links ein unberührtes Corp. Int. (mikroskopisch festgestellt).

No. 13, 1908. Am 5. 7. belegt. 10. 7. rechts 1, links 4 Corp. lut. ausgebrannt. 17. 7. Section: Linkes Horn enthält 4 Kammern vom 12. Tag, von denen 2 im Rückgang begriffen sind. Rechtes Horn leer. Rechtes Ovarium enthält 3 unberührte Corp. lut.

No. 14, 1908. Am 4. 7. belegt. 10. 7. rechts 5 Corp. lut ausgebrannt. 17. 7. Section: rechts 5, links 1 Kammer vom 14. Tag; rechts 1 Kammer im Rückgang. Rechts zwei unberührte und mehrere unvollkommen ausgebrannte Corp. lut. Im linken Ovarium, vom lateralen $\mathrm{Pol}$ durch eine Einschnürung fast vollkommen getrennt, ein schönes Corp. lut.

No. 17, 1908. Am 16. 7. belegt. 22. 7. je 3 Corp. Iut. ausgebrannt. 30. 7. Section: Rechts 3 Kammern vom 14. Tag. Rechtes Ovarium enthält 2 unberührte Corp. lut.

No. 26, 1908. Am 30. 8. belegt. 2. 9. Ausbrennung von reichlichen Corp. lut. auf beiden Seiten. 9. 9. Section: Links 3 Kammern vom 11. Tag. Linkes Ovarium enthält 4 unberührte Corp. lut. (mikroskopisch verificirt).

No. 37. 1909. Am 30. 6. belegt. 3. 7. je 1 Corp. lut. herausgehoben. 7. 7. Section: links 3, rechts 8 Kammern vom 8. Tag. Links 2. rechts 4 unberührte Corp. lut.

No. 38, 1909. Am 30. 6. belegt. 3. 7. rechts 6, links 3 Corp. lut. enthälst. 7. 7. Section: Rechts 6, links 5 erbsengrosse Kammern. Rechts 3, links 4 unverletzte Corp. lut.

No. 43, 1909. Am 9. 7. belegt. 14. 7. links 4 Corp. lut. herausgelöst. 19. 7. Section: Keine Gravidität. Rechts 2, links 4 Corp. lut., die nur auf dem Durchschnitt zu sehen sind.

No. 45, 1909. Am 11. 7. belegt. 17. 7. linkes Ovarium mit 3 Corp. lut. exstirpirt; rechts 1 Corp. lut. herausgehoben. 22. 7. Section: Keine Gravidität. Rechts eine Corp. lut.-verdächtige Stelle, mikroskopische Untersuchung bestätigt ein schönes Corp. lut. 
712 L. Fraenkel, Neue Experimente zur Function des Corpus luteum.

No. 46, 1909. Am 19. 7. belegt. 25. 7. je 2 Corp. lut. ausgebrannt. 29. 7. Section: Keine Gravidität. Auf jedem Ovarium ein unverletztes Corp. lut.

\section{Castrationen nach der Ei-Insertion.}

No. 1, 1904. Am 8. 3. belegt. 22. 3. rechts 3, links 1 Kammer. Castration; rechts 4 , links 3 Corp. lut. Gravidität geht zu Grunde.

No. 3, 1904. Am 10. 3. kelegt. 24. 3. rechts 2, links 7 Kammern. Castration: rechts 2, links 6 Corp. lut. Gravidität geht zu Grunde.

No. 5, 1904. Am 16. 3. belegt. 27. 3. rechts 6, links 2 Kammern. Castration: rechts 6, links 4 Corp. lut. Gravidität geht zu Grunde.

No. 6, 1904. Am 20. 3. belegt. 30. 3. rechts 3, links 0 Kammern. Castration: rechts 2, links 5 Corp. lut. Gravidität geht zu Grunde.

No. 7, 1904. Am 25. 3. belegt. 5. 4. rechts 2 Kammern. Castration: rechts 3, links 5 Corp. lut. Gravidität geht zu Grunde.

No. 9, 1904. Am 31. 3. belegt. 8. 4. rechts 4, links 6 Kammern. Castration. rechts 5, links 6 Corp. lut. Gravidität geht zu Grunde-

No. 10, 1904. Am 31. 3. belegt. 8. 4. rechts 6, links 1 Kammer. Castration: rechts 6, links 1 Corp. Iut. Gravidität geht zu Grunde.

No. 42, 1904. Am 26. 5. belegt. 3. 6. rechts 1, links 6 Kammern. Castration: rechts 1, links 6 Corp. lut. Gravidität geht zu Grunde.

No. 43, 1904. Am 25. 5. belegt. 3. 6. rechts 4, links 5 Kammern. Castration: rechts 4, links 5 Corp. lut. Gravidität gelit zu Grunde.

No. 44, 1904. Am 22. 5. belegt. 3. 6. rechts 2, links 4 Kammern. Castration: Rechts 2, links 4 Corp. lut. Graviditat geht zu Grunde.

No. 46, 1904. Am 28. อ. belegt. 10. 6. rechts 1, links 3 Kammern. Castration: Rechts 2, links 3 Corp. Iut. Graviditat geht zu Grunde.

No. 47, 1904. Am 28. 5. belegt. 10. 6. rechts 3, links 2 Kammern. Castration: rechts 3 , links 2 Corp. lut. Gravidität geht zu Grunde.

No. 48, 1904. Am 27. 5. belegt. 10. 6. rechts 7, links 2 Kammern. Castration: rechts 7, links 2 Corp. lut. Gravidität geht zu Grunde.

No. 55, 1904. Am 18. 7. belegt. 28. 7. rechts 2, links 6 Kammern. Castration: rechts 2 , links 6 Corp. lut. 19. 8. Section: Gravidität geht zu Grunde.

No. 9, 1906. Am 1. 5. belegt. 0. 5. rechts 7, links 6 Kammern. Castration: Rechts 7, links 6 Corp. lut. 15. 5. Section: Keine Gravidität.

No. 24, 1906. Am 4. 6. belegt. 12. 6. je 6 Kammern. Castration: 18. 6. Seetion: Keine Gravidität.

No. 24, 1907. Am 28. 5. belegt. 9.6. 7 Kammern. Castration. 13.6. Section: Keine Gravidität.

No. 1, 1910. Am 30. 12. belegt. 12. 1. je 6 Kammern. Castration. 17. 1. Section: Kammern rückgebildet.

No. 3, 1910. Am 5. 1. belegt. 17. 1. rechts 5, links 4 Kammern. Castration. 22. 1. Section: Kammern im Rückgang.

\section{Totalentfernung der Corp. lut. nach der Ei-Insertion.}

No. 11. 1904. Am 31. 3. belegt. 13. 4. links 3, rechts O Kammern. Links 3, rechts 0 Corp. lut. ausgebrannt. 18. 4. Section: (Tod durch Pleuritis) Kammern in Rückbildung. Keine Corp. Iut.

No. 23, 1904. Am 1. 5. belegt. 10. 5. links 5, rechts 7 Kammern. Links 4 , rechts 7 Corp. lut. ausgebrannt. 28. 5. Section: (Tod an Pneumonie). Keine Gravidität, keine Corp. lut. 
No. 33, 1904. Am 9. 5. belegt. 17. 5. links 2, rechts 6 Kammern. Links 2, rechts 6 Corp. lut. ausgebrannt. 6. 6. Section: (Tod an Pericarditis). Keine Gravidität, keine Corp. lut.

No. 3, 1905. Am 2. 5. belegt. 10. 5. links 2 Kammern. Links 2 Corp. lut. ausgebrannt. 15. 5. Section: Keine Gravidität, keine Corp. lut.

No. 9, 1905. Am 21. 6. belegt. 1. 7. links 5, rechts 2 Kammern. Links 5, rechts 2 Corp. lut. ausgebrannt. 9. 7. Section: Keine Gravidität, keine Corp. lat.

No. 1, 1906. Am 16. 2. belegt. 25. 2. links 5, rechts 3 Kammern. Links 5, rechts 3 Corp. Jut. ausgebrannt. 13. 3. Section: Keine Gravidität, keine Corp. lut.

No. 2, 1906. Am 18. 2. belegt. 26. 2. links 3, rechts 7 Kammern. Links 3, rechts 7 Corp. lut. ausgebrant. 13. 3. Section: Keine Gravidität, keine Corp. lut.

No. 3, 1906, Am 19. 2. belegt. 27. 2. je 2 Kammern. Je 4 Corp. lut. ausgebrannt. 13. 3. Section: Keine Graviditat, keine Corp. lut.

No. 4, 1906. Am 2. 3. belegt. 10. 3. rechts 4, links 5 Kammern. Rechts 4, links 5 Corp. lut. ausgebrannt. 26. 3. Section: Keine Gravidität, keine Corp. lut.

No. 2, 1907. Am 5. 4. belegt. 11. 4. 2 Kammern von $5-7 \mathrm{~mm}$ im linken Horn. Im linken Ovarium 4, im rechten 2 Corp. lut. aus:gebrannt. 16. 4. Section: Keine Graviditiat, keine Corp. lut.

No. 3, 1907. Am 5. 4. belegt. 11. 4. im rechten Horn eine Eikammer von ca. $6 \mathrm{~mm}$ Durchmesser. Je 3 Corp. lut. ausgebrannt. 16. 4. Section: Uterus leer. Ovarien luteopriv.

No. 4, 1907. Am 6. 4. belegt. 12. 4. im rechten Horn 2 Kammern von $7 \mathrm{~mm}$ Durchmesser. Rechts 4 , links 1 Corp. lut. ausgebrannt. 16. 4. Section: Keine Gravidität, keine Corp. lut.

No. 32, 1908. Am 3. 12. belegt. Am 15. 12. rechts 5, links 4 Kammern. 9 Corp. lut. entbülst. 22. 12. Section: Alle Kammern in Rückbildung. Keine Corp. lut.

No. 1, 1909. Am 24. 12. belegt. 5. 1. rechts 5, links 4 Kammern. Rechts 4, links 5 Corp. Iut. enthülst. 11. 1. Section: Kammern in Rückbildung, keine Corp. lut.

No. 2, 1909. Am 17. 1. belegt. 26. 1. links 1, rechts 4 Kammern. Links 3, rechts 5 Corp. lut. enthülst. 31. 1. Section: Kammern verschwunden, keine Corp. Iut.

No. 3, 1909. Am 20. 1. belegt. 31. 1. links 2, rechts 5 Kammern. Links 1, rechts 8 Corp. lut. enthülst. 7. 2. Section: Keine Gravidität, Ovarien Iuteopriv.

No. 4, 1909. Am 16. 2. belegt. 26. 2. links 1, rechts 2 Kammern. Links 5, rechts 4 Corp. lut. enthülst. 4. 3. Section: Kammern in Rückbildung, keine Corp. lut.

No. 6, 1909. Am 20. 2. belegt. 2. 3. rechts 5, links 2 Kammern. Je 4 Corp. lut. enthülst. 7. 3. Section: Kammern in Rückbildung, keine Corp. lut.

No. 7, 1909. Am 1. 3. belegt. 9. 3. links 2 Kammern. Links 2 Corp. lut. enthülst. Rechtes Ovarium mit 7 Corp. Iut. wird exstirpirt. 14. 3. Section: 2 stark verkleinerte Eier im Uterus, keine Corp. Jut.

No. 8, 1909. Am 21. 3. belegt. 30. 3. rechts 7, links 3 Kammern. Rechts 7, links 4 Corp. lut. enthülst. 3. 4. Section: Eier verschwunden, Ovarien ohne Corp. lut. 
Fo. 9, 1909. Am 22. 3. belegt. 1. 4. rechts 7, links 4 Kammern Links 4 Corp. lut. enthülst. Rechtes Ovarium mit 8 Corp. lut. entfernt. 6. 4. Section: Uterus leer. Ovarium ohne Corp. lut.

No. 10, 1909. Am 27. 3. belegt. 6. 4. rechts 1, links 4 Karnmern. Rechts 1, links 4 Corp. lut. enthülst. 10. 4. Section: Uterus leer. Ovarien ohne Corp. lut.

No. 11, 1909. Am 28. 3. belegt. 6. 4. rechts 3, links 4 Kammern. Rechts 3, links 4 Corp. lut. ausgeschält. 10. 4. Section: Eier im Rückgang. Ovarien ohne Corp. lut.

No. 12, 1909. Am 31. 3. belegt. 8. 4. rechts 4, links 6 Kammern. Rechts 5, links 5 Corp. Iut. ausgeschält. 13. 4. Section: Uterus leer; Ovarien luteopriv.

No. 16, 1909. Am 11. 5. belegt. 22. 5. links 6, rechts 3 Kammern. Links 6 , rechts 3 Corp. lut. herausgegraben. 29. 5. Section: Uterus leer. Ovarien luteopriv.

No. 17, 1909. Am 12. 5. belegt. 22. 5. je 4 Kammern. Je 4 gelbe Körper ausgeschält. 29. 5. Section: Kammern in Rückbildung. Keine gelben Körper.

No. 18, 1909 . Am 12. 5. belegt. 22. 5. rechts 4, links 1 Kammer. Rechts 4 , links 2 Corp. lut. entfernt. 29. 5. Section: Uterus leer. Ovarien luteinfrei.

No. 19, 1909. Am 13. 5. belegt. 23. 5. rechts 2, links 5 Kammern. Rechts 1, links 5 Corp. lut. herausgehoben. 29. 5. Section: Kammern im Rückgang. Ovarien ohne Corp. lut. (mikroskopisch verificirt, weil makroskopische Beurtheilung nicht ganz sicher war.)

No 20, 1909. Am 15. 5. belegt. 25. 5. recbts 3, links 6 Kammern. Rechts 3, links 6 Corp. lut. herausgehoben. 29. 5. Section: Eier im Rückgang. Ovarien luteopriv.

No. 21, 1909. Am 15. 5. belegt. 26. 5. rechts 5, links 4 Kammern. Rechts 6, links 5 Corp. lut. herausgehoben. 29. 5. Section: Eier im Rückgang. Keine Corp. lut.

No. 22, 1909. Am 15. 5. belegt. 25. 5. rechts 2, links 5 Kammern. Rechts 3, links 6 Corp. lut. ausgehülst. 29.5. Section: Kammern fast ganz zurückgebildet. Keine Corp. lut.

No. 24, 1909. Am 26. 5. belegt. 5. 6. je 5 Kammern. Rechts 6, links 5 Corp. lut. herausgehoben. 10.6. Section: Eier stark zurückgebildet. Ovarien luteopriv.

No. 26, 1909. Am 27. 5. belegt. 5. 6. rechts 2, links 4 Kammern. Rechts 3, links 6 Corp. lut. entnommen. 10. 5. Section: Kammern in Rückbildung. Ovarien luteinfrei.

No. 27,1909 . Am 25. 5. belegt. 5. 6. rechts 4, links 8 Kammern. Rechtes Ovarium mit 14 Corp. lut. exstjrpirt. Links 8 Corp. lut. entfernt. 10. 6. Section: Eier verschwunden. Das linke Ovarium ohne gelbe Körper.

No. 29, 1909. Am 31. 5. belegt. 9.6. links 10 Kammern. Links 10, rechts 6 Corp. lut. herausgehoben. 14. 6. Section: Kammern im Rückqang. Ovarien frei von Luteingewebe.

No. 32, 1909. Am 12. 6. belegt. 21. 6. links 2, rechts 4 Kammern. Links 2 Corp. lut. enthülst. Rechtes Ovarium mit 4 Corp. lut. entfernt. 26.6. Section: Eier in Rückbildung. Ovarium ohne gelbe Körper.

No. 34 , 1909. Am 12. 6. belegt. 23. 6. rechts 3, links 6 Kammern. 
Rechts 3, links 6 gelbe Körper entfernt. 26. 6. Section: Kammern im Rückgang. Ovarien luteopriv.

No. 35, 1909. Am 14. 6. belegt. 23. 6. links 3, rechts 4 Kammern. Links 3 Corp. lut. entfernt. Rechtes Ovarium mit 5 Corp. lut. exstirpirt. 28. 6. Section: Kammern in Rückbildmng. Linkes Ovarium frei von Corp. lut.

No. 39, 1909. Am 30. 6. belegt. 11. 7. rechts 3, links 1 Kammer. Rechts 3, links 6 Corp. Iut. entfernt. 16. 7. Section: Eier in Rückbildung. Ovarien luteopriv.

No. 40, 1909. Am 2. 7. belegt. 11. 7. rechts 4, links 7 Kammern. Rechts 5 , links 7 gelbe Körper enthülst. 16. 7. Section: Kammern im Rückgang. Ovarien frei von Corp. Jut. Am lateralen Pol des rechten Ovarium befindet sich ein grosser Hohlraum mit weisser, verdickter Wand. Mikroskopisch: Atretischer Follikel.

No. 49, 1909 . Am 14. 11. belegt. 23. 11. rechts 3, links 7 Kammern. Rechts 4 Corp. lut. enukleirt. Linkes Ovarium mit 6 Corp. Iut. exstirpirt. 29, 11. Section: Uterus leer. Ovarien ohne Corp. lut.

No. 2, 1910. Am 29. 12. belegt. 12. 1. rechts 2, links 8 Kammern. Rechts 2 Corp. lut. enthülst. Linkes Ovarium mit reichlich Corp. lut. exstirpirt. 17. 1. Section: Rechts 2, links 7 Kammern im Rückgang. Rechtes Ovarium luteopriv.

No. 4, 1910. Am 7. 2. belegt. 21. 2. rechts 4, links 6 Kammern. Rechts 5, links 6 Corp. lut. enthülst. 25. 2. Section: Kammern in Rückbildung. Ovarien obne Corp. Iut. Einige etwas verdickte, weissliche, kugelige Partien erweisen sich mikroskopisch als Teile der glande interstitielle.

No. 16, 1910. Am 9. 5. belegt. 21. 5. links 4, rechts 0 Kammern. Links 4, rechts 1 Corp. lut. enthülst. 26. 5. Section: Kammern im Rückgang. Ovarien luteopriv.

No. 17, 1910. Am 14. 5. belegt. 27. 5. rechts 0, links 3 Kammern. Rechts 4, links 7 Corp. lut. enhülst. 1. 6. Section: Kammern rückgebildet. Linkes Ovarium luteopriv, rechtes makroskopisch zweifelhaft, mikroskopisch: frei von Corp. lut.

No. 22, 1910. Am 26. 5. belegt. 8. 6. rechts 6, links 4 Kammern. Rechts 7 , links o Corp. lut. enthülst. 14.6. Section: Eier in vollkommener Rückbildung. Ovarien ohne Corp. lut.

No. 27, 1910. Am 1. 6. belegt. 14. 6. rechts 3, links 9 Kammern. Rechts 3, links 9 Corp. lut. herausgehoben. 19. 6. Section: Eier sehr stark im Rückgang. Ovarien frei von Luteingewebe.

No. 31, 1910. Am 24. 6. belegt. 7. 7. rechts 4, links 3 Kammern. Rechts 4, links 3 Corp. lut. enukleirt. 12. 7. Section: Rückbildung aller Kammern. Ovarien luteinfrei.

No. 32, 1910. Am 26. 6. belegt. 9. 7. je 4 Kammern. Rechts 4, links 5 Corp. lut. stumpf entnommen. 16. 7. Section: Uterus leer. Ovarien luteopriv.

No. 33, 1910. Am 28. 6. belegt. 10. 7. links 3, rechts 6 Kammern. Links 3, rechts 6 Corp. lut. ausgehülst. 16. 7. Section: Eier abgestorben. Ovarien luteopriv.

No. 34, 1910. Am 28. 6. belegt. 10. 7. rechts 1, links 0 Kammern. Rechtes Ovarium mit 4 Corp. lut. exstirpirt. Links 1 Corp. lut. ausgegeben. 16. 7. Section: Kammern in Rückbildung. Linkes Ovarium luteopriv. 
No. 35, 1910. Am 29. 6. belegt. 11. 7. links 4, rechts 5 Kammern. Linkes Ovarium mit 8 Corp. Jut. exstirpirt, rechts 9 Corp. Iut. enthülst. 16. 7. Section: Kammern in Rückbildung. Linkes Ovarium luteopriv.

\section{Partielle Entfernungen der Corp. lut. nach der Ei-Insertion.}

No. 10, 1904. Am 16. 4. belegt. 30. 4. links 4, rechts 1 Kammer. Links 4, rechts 1 Corp. lut. ausgebrannt. 15. 5. Geburt eines ausgetragenen Jungen. 19. 5. Exitus. Section: Uterus leer. Am linken Ovarium ein unausgebranntes Corp. lut.

No. 28, 1904. Am 2. 5. belegt. 13. 5. links 0, rechts 5 Kammern. Links 7, rechts 5 Corp. lut. ausgebrannt. 22.5. Section: (Tod an Peritonitis). Eikammern weiter gewachsen. Einige Corp. lut. sind nur ganz oberflächlich verschorft.

No. 7, 1906. Am 6. 4. belegt. 14. 4. rechts 2, links 6 Kammern. Rechts 2, links 5 Corp. lut ausgebrannt. 23. 4. Section: 2 Kammern vom 16. Tag, die anderen abgestorben. 1 absolut intactes Corp. lut.

No. 11. 1906. Am 9. 4. belegt. 18. 4. je 5 Kammern. Rechts 3, links 4 Corp. lut. ausgebrannt. 25. 4. Section: Rechts 4, links 2 Kammern weitergewachsen. Rechts 2, links 1 Corp. lut.

No. $13,1906 . \Lambda \mathrm{m} \mathrm{17.} \mathrm{4.} \mathrm{belegt.} \mathrm{25.} \mathrm{4.} \mathrm{rechts} \mathrm{4,} \mathrm{links} 6$ Kammern. Rechts 2, links 6 Corp. lut. ausgebrannt. 2. 5. Section: Rechts 1 Kammer vom 17. Tag, alle andern im Rückgange. Im rechten Ovarium 2 unberührte Corp. lut.

No. 16, 1906. Am 16. 4. belegt. 24. 4. links 3, rechts 4 Kammern. Links 3, rechts 4 Corp. lut. ausgebrannt. 2. 5. Section: Keine Gravidität. Ein unberührtes Corp. lut. im rechten Ovarium.

No. 5, 1909. Am 18. 2. belegt. 2. 3. links 6 Kammern. Links 6, rechts 2 Corp. Iut. herausgehoben. 7. 3. Seckion: 2 Kammern vom 17. Tag, 4 im Rückgang. Linkes Ovarium entbält 2 unberührte Corp. lut. (Direct am Hilus ovarii, daher durch den Ligamentansatz fast ganz verdeckt).

No. 14, 1909. Am 5. 5. belegt. 17. 5. rechts 3, links 2 Kammern. Rechts 3, links 2 Corp. Jut. ausgehülst. 21. 5. Section: Alle Kammern im Rückgang, Je 1 unversehrtes Corp. Iut.

No. $15,1909$. Am 5. 5. belegt. 17. 5 . rechts 5 , links 7 Kammern. Rechts 6 , links 7 Corp. lut. ausgeschält. 21. 5. Section: Lateralste Kammer rechts weitergewachsen, alle anderen im Rückgang. Links 2 Corp. lut.

No. 23, 1909. Am 20. 5. belegt. 29. 5. rechts 7, links 4 Kammern. Recbts 6, links 5 Corp. lut. enucleirt. 3. 6. Section: Rechts 2, links 3 Kammern vom 13. Tag. In jedem Ovarium eine auf Corp. lat. verdächtige Kugel wird mikroskopirt und bestätigt sich als sulches.

No. 25, 1909. Am 27. 5. belegt. 5. 6. rechts 4, links 5 Kammern. Rechts 6 , links 7 Corp. lut. enthülst. 10. 5. Section: Kammern weitergewachsen. In jedem Ovarium 3 unberührte Corp. lut.

No. 33, 1909. Am 12.6. belegt. 21. 6. rechts 3, links 2 Kammern. Rechts 5, links 6 Corp. lut. herausgehoben. 26. 6. Section: 2 Kammern weitergewachsen. Ein unberührtes Corp. lut. am rechten Ovarium. 
No. 47, 1909. Am 19. 7. belegt. 28. 7. rechts 7, links 6 Kammern. Rechts 8, links 7 Corp. lut. enucleirt. 2. 8. Section: Links 7, rechts 3 Kammern vom 13. Tag und 1 zurückgegangene. Auf der Oberfläcbe des linken Ovarium 2 unberührte Corp. lut. ohne weiteres zu sehen. Zupft man den dünnen Fibrinmantel, der das rechte Ovarium einhüllt, ab, so kommt anch bald ein intactes Corp. Iut. zu Gesicht.

No. 51, 1909. Am 29. 11. belegt. 12. 12. links 2, rechts 4 Kammern Links 1 Corp. lut. enucleirt, rechtes Ovarium mit 4 Corp. lut. exstirpirt. 17. 12. Section: Keine Gravidität. Links 1 Corp. lut. mikroskopisch bestätigt.

No. 6, 1910. Am 25. 1. belegt. 5. 2. rechts 8, links 4 Kammern. Rechts 7, links 4 Corp. lut. herausgehoben. 11. 2. Section: Keine Gravidität. Rechts ein unberührtes Corp. lut. (mikroskopisch verificirt).

No. 7, 1910. Am 1. 3. belegt. 11. 3. rechts 10, links 5 Kammern. Rechtes Orarium mit 10 Corp. Int. exstirpirt. Links 4 gelbe Körper enucleirt. 15. 3. Section: 1 Kammer weiter entwickelt, alle anderen im Rückgang. An Iateralen Ende des linken Ovarium ein schönes mikroskopisch bestätigtes Corp. lut., welches auf dem Hauptsectionsschnitt nicht sichtbar ist.

No. 24, 1910. Am 28. 5. belegt. 10. 6. rechts 8, links 4 Kammern. Links 4 , rechts 5 Corp. lut. enthülst, wobei das 5 . aus der Tiefe mit hervorgezogen wird. 14.6. Section: Links 4, rechts 8 Kammern weitergewachsen. Linkes Ovarium luteopriv. Das rechte Ovarium enthält 2 äusserlich sichtbare Corpt. lut; eines am lateralen Pol und eines in der Tiefe.

\section{Neue Conception nach Igniexcision der Corp. lut.}

No. 12, 1904. Am 5. 4. belegt. 15. 4. rechts 8, links 5 Kammern, Rechts 8, links 5 Corp. lut. ausgebrannt. Kein Wurf. Am 28. 5. wieder belegt. 9. 6. Section: Links 3, rechts 7 frische Kammern. Rechts 7, links 3 frische Corp. lut. Die ron der Ausbrennung herrührenden, blauschwarı pigmentirten Narben sind noch zu seben.

No. 14, 1904. Am 12. 4. belegt. 22. 4. rechts 4, links 5 Kammern, Rechts 4 , links 5 Corp. lut. ausgebrannt. Das Tier wirft nicht, wird am 18. 5. wiederbelegt. 9. 6. Section: Links 1, rechts 2 frische Kammern. 3 intacte Corp. lut. auf den Ovarien.

No. 15, 1904. Am 2. 4. belegt. 22. 4. je 3 Kammern. Rechts 3, links 5 Corp. Iut. ausgebrannt. Kein Wurf. 13. 5. Neu belegt. 9. 6. Section: Links 1, rechts 3 Kammern. Links 1, rechts 3 frische Corp. lut. dazwischen alte Brandschrofe.

No, 16, 1904. Am 1.4. belegt. 22. 4. Rechts 7, Iinks 1 Kammer. Rechts 7, links 1 Corp. lut. ausgebrannt. Das Tier wirft nicht, 13. 5. widerbelegt. 27. 5. Section: Rechts 1, links 10 Kammern. Rechts 1, links 10 Corp. lut.

No. 17, 1904. Am 31. 3. belegt. 22. 4. Rechts 4, links 1 Kammer. Rechts 4, links 2 Corp. lut. ausgebrannt. Wurf nicht beobachtet. 17. 6. wiederbelegt. 26.6. Section (Tod an linksseitiger OberlappenPneumonie). Links 5, rechts 2 Kammern. Links 4, rechts 3 Corp. lut., dazwisehen schiefrig pigmentirte Narben. 
No. 20. 1904. Am 16. 4. belegt. 30. 4. Rechts 3, links 2 Kammern. Links 3, rechts 4 Corp. lut. ausgebrannt. 13. 5. Morgens Geburt von 5 ausgetragenen Jungen. Abends belegt. 8. 6. Section: Im rechten Horn 1 Kammer. Auf den Ovarien mehrere schiefrige SteIlen und 2 frische Corp. lut.

No. 21, 1904. Am 23. 4, belegt. 3. 5. Rechts 3, links 7 Kammern. Rechts 3, links 7 Corp. lut. ausgebrannt. 22. 5.8 Junge geboren. Am 25. 5. belegt. 8. 6. Section: Links 2, rechts 6 Kammern. Links 2, rechts 6 Corp. lut.

No. 26, 1904. Am 20. 4. belegt. 12. 5. Rechts 4, links 1 Kammer. Rechts 4, links 1 Corp. lut. ausgebrannt. Wurf nicht beobachtet. 7. 6. neu belegt. 21. 6. Section: Je 3 Kammern sowie einige schöne Corp. lut. und einige schiefrige Stelien.

No. 27, 1904. Am 29 4. belegt. 12. 5. Rechts 2, links 6 Kammern. Rechts 2, links 6 Corp. lut. ausgebrannt. Kein Wurf. 3. 7. belegt. 18. 7. Section: Links 6 , rechts 2 Kammern, denen frische Corp. lut. entsprechen. Auf beiden Ovarien schiefrige Stellen.

No. 29, 1904. Am 3.5. belegt. 13.5.je4Kammern. Je4 Corp. lut. ausgebrannt. Geburt nicht eingetreten. 22. 6. belegt. 7. 7. Section: Links 1. rechts 3 Kammern. Auf beiden Ovarien einige schiefrige Stellen und frische Corp. lut.

No. 30. 1904. Am 3. 5. belegt. 13. 5. Links 2, rechts 2 Kammern. Rechts 4, links 3 Corp. lut. ausgebrannt. Kein Wurf. 10. 7. belegt. 22. 7. Section: Rechts 5, links 2 Kammern. Auf den Ovarien Corp. lut. und je 1 schwarzbraunes, stecknadelkopforosses Feld.

No. 31. 1904. Am 5. 5. belegt. 14 5. Links 7 Kammern. Links 5, rechts 1 Corp. lut. ausgebrannt. 31.5. Wurf von 7 ausgetragenen lebenden Jungen, und neu belegt. Am 11. 6. Section: Gravidität.

No. 32, 1904. Am 4. 5. belegt. 16. 5. Rechts 5, links 3 Kammern. Rechts 5, links 3 Corp. lut. ausgebrannt. Kein Wurf. 20.6. wiederbelegt. 2. 7. Section: Rechts 5, links 1 Kammer. Rechts 5, links 1 Corp. lut. und strichförmige schwarze Narben.

No. 34. 1904. Am 11.5. belegt. 21. 5. Rechts 7, links 5 Kammern. Rechts 7 , links 5 Corp. Jut. ausgebrannt. 11. 6 werden 3 ausgetragene Junge geboren. 12. 6. belegt, ca. 10 Tage später gravid befunden.

No. 36, 1904. Am 12. 5. belegt. 27. 5. Rechts 6, links 4 Kammern. Rechts 6 , links 4 Corp. Iut. ausgebrannt. Kein Wurf. Später wiederbelegt, wirft am 2. 8., 25.9. 9 bezugsweise 6 ausgetragene Junge. 1. 10. Section: Ovarien ohne frische Corp. lut., etwas adhärent.

No. 37, 1904. Am 14.5. belegt. 26.5. Je 4 Kammern. Je 4 Corp. lut. ausgebrannt. Kein Wurf. 7. 7. belegt. Am 5. 8. 7 lebende Junge und am 30. 9. 4 ausgetragene Junge. 30. 9. belegt. 8. 10. zweite Laparotomie: Keine Gravidität; normale Verbältnisse.

No. 38, 1904. Am 19. 5. belegt. 28. 5. Rechts 7, links 3 Kammern. Rechts 7 , links 3 Corp. lut. ausgebrannt. Geburt erfolgte nicht. 23. 7. wiederbelegt. 21. 8. von neuem geworfen.

No. 39. 1909. Am 19. 5. beleot. 28. 5. Rechts 5, links 4 Kammern. Rechts 3 , links 4 Corp. lut. ausgebrannt. Kein Partus. 22. 7. belegt. 20. 8. Ausgetragene Junge geboren.

No. 40, 1904. Am 17. 5. belegt. Am 28. 5. je 8 Kammern. Corp. Iut. nicht vollkommen ausgebrannt. 17. 6. werden 3 Junge geworfen. In demselben Jahre von neuem belegt und geworfen. 
No. 8, 1905. Am 22. 6. belegt. 1. 7. 3 bezugsweise 2 Follikel ausgebrannt. 25. 7. von neuem belegt. 3. 8. Links 1, rechts 3 Kammern, je 2 Corp. lut.

No. 28, 1906. Am 14. 5 belegt. 20. 5. je 2 wenig prominente Corp. lut. ausgebrannt. Kein Partus. 17. 6. wiederbelegt. 26. 6. zweite Laparotomie. Links 5 Kammern, entsprechend Corp. Iut. Rechtes Ovarium luteopriv.

In folgenden Fällen trat keine neue Conception ein:

No. 22, 1904. Am 22. 4. belegt. 3. 5. rechts 4, links 6 Kammern. Rechts 3, links 6 Corp. lut. ausgebrannt. In der Zwischenzeit kein Wurf; wiederholt Coitus. 28.9. Section: Normaler Genitalbefund, gesunde Organe.

No. 35, 1904. Am 11. 5. belegt. 21. 5. Rechts 6, links 5 Kammern. Rechts 6, links 5 Corp. Iut. ausgebrannt. In der Zwischenzeit mit dem Bock oft zusammengesetzt. Krepiert den 23. 6. Section: Tuberculöse Pleuropnemmonie und Pericarditis. Keine Gravidität.

No. 41, 1904. Am 25. 5. belegt. 3. 6. Rechts 6, links 3 Kammern. Rechts 6, links 3 Corp. lut. ausgebranut. In der Folge kein Wurf, mehrfach von neuem erfolglos belegt.

\section{Wirkung der Narkose allein, Laparotomie, Brandschorfe neben die Corpora lutea}

No. 2, 1904. Am 22. 3. Laparotomie: 3 Kammern vom 22. Tag. Einige Tage später normaler Partus.

No. 24,1904 . Am 30. 4. belegt. 10.5. Rechts 2, links 4 Kammern. Laparotomie. 23. 5. Normaler Partus ad terminum.

No. 11, 1905. Am 5. 7. belegt. 9. 7. Laparotomie. Gravidität in den letzten Tagen, 12. 7. Geburt lebender Junge. 13. 7. Von neuem belegt.

No. 10, 1906. Am 9. 4. belegt. 17. 4. Links 2 Kammern; links 3 Löcher neben die 3 sehr schönen Corp. lut. gebrannt. 25. 4. Section: Links 2 Kammern weitergewachsen. Je 4 wohlerhaltene Corp. lut:

No. 12, 1906. Am 15. 4. belegt. 23. 4. Rechts 7, links 4 Kammern. Links 2, rechts 3 tiefe Löcher neben die Corp. lut. gebrannt. 4. 5. Section: Rechts 7, links 4 Kammern weiter entwickelt. Reichlich unberübrte Corp. lut. auf beiden Seiten.

No. 17, 1906. Am 3. 5. belegt. 9. 5. Links 3, rechts 2 Löcher neben die nicht sehr typischen Corp. lut. gebrannt. 13. 5. Section: Keine Gravidität: Corp. lut. unberührt.

No. 18, 1906. Am 5. 5. belegt. 11. 5. Je 5 tiefe Löcher neben die (rechts 6, links 3) Corp. lut. gebrannt. 16. 5. Section: Rechts 3, links 6 Kammern vom 11. Tag.

No. 34, 1906. Am 16.7 belegt. 22. 7. Laparotomie: Mehrere ganz junge Ei-Kammern. Das Thier wirft ad terminum.

No. 13, 1907. Am 25. 4. belegt. 1.5. Im linken Horn eine 3 Wochen alte Gravidität, die weitergeht.

No. 14, 1907. Am 25. 4. belegt. 1. 5. Narkose. Wegen krampfhafter Zwerchfell-Contractionen Operation unterlassen. Wirft ad terminum. 
720 L. Fraenkel, Neue Experimente zur Function des Corpus luteum.

No. 32, 1907. Am 22. 6. belegt. 28. 6. Mehrere Kammern vom 11. Tag, durch Laparotomie constatirt. Graviditat gent weiter.

No. 20, 1908. Am 26. 7. belegt. 1. 8. Erste Laparotomie: Eine grosse Anzahl ganz junger Kammern. 14. 8. Zweite Laparotomie: 10 Kammern von Taubeneigrösse.

No. 28, 1910. Am 6. 6. belegt. 19. 6. Mehrere Eikammern ad terminum. 21. 6. Wurf lebender Junge.

No. 29, 1910. Am 4. 6. belegt. 19. 6. Mehrere fast ausgetragene Eikammern und solche in Rückbildung. Nach einigen Tagen Wurf lebender Junge.

\section{Operationen nach dem 14. Tag.}

No. 8, 1904. Am 22. 3. belegt. 6.4. je 6 Kammern. Links 7 , rechts 5 Corp. lut. Castration. Rückbildung der Kammern.

No. 25, 1904. Am 21. 4. belegt. 12. 5. links 4, rechts 2 Kammern. Links 3, rechts 2 Corp. lut. ausgebrannt. 15.5. Section: (Tod aus unbekannter Ursache) Kammern weiter entwickelt. Keine Corp. lut.

No. 5, 1910. Am 17. 2. belegt. 5. 3. rechts 5, links 0 Kammern. Rechtes Ovarium mit 5 Corp. Iut. exstirpirt. Linkes Ovarium ohne Corp. lut. wird zurückgelassen. 11. 3. Section: 4 rüickgebildete, eine fortschreitende Gravidität. Im rechten Stumpf findet sich ein erbsengrosses Gewebsstück, welches auf dem Durchschnitt wie 3 confluirende Corp. lut. erscheint, mikroskopisch sich aber als Fettgewebe erweist.

No. 9, 1910. Am 13. 4. belegt. 29. 4. rechts 5, links 2 Kammern. Rechts 6 , links 4 Corp. lut. ausgebrannt. 6. 5. Section: Keine Gravidität. Keine Corp. lut.

No. 12, 1910. Am 14. 4. belegt. 2. 5. rechts 9, links 10 Kammern. Castration. 6. 5. Section: Rückgang aller Kammern.

No. 13, 1910. Am 16. 4. belegt. 2. 5. rechts 1, links 2 Kammern. Rechts, 3, links 6 Corp. lut. entbülst. 6.5. Section: Kammern im Rückgang. Ovarien ohne Corp. lutea.

No. 15, 1910. Am 1. 5. belegt. 17. 5. links 6, rechts 9 Kammern. Links 6, rechts 8 Corp. lut. enthüIst. 23. 5. Section: Rückgang aller Kammern. Ovarien obne Corp. lut.

No. $20,1910 . \mathrm{Am}$ 19. 5. belegt. 3. 6 . rechts 5, links 4 Kammern. Rechts 3, links 4 Corp. lut. enthülst. 3 Tage später Abort einer normal entwickelten Frucht. 7. 6. Section: Rückbildung aller übrigen Kammern. Linkes Ovarium luteopriv. Rechtes auf der Oberfläche luteopriv erscheinend, enthält auf dem Sectionsschnitt 2 typische Corpora Iutea.

No. 21, 1910. Am 21. 5. belegt. 5. 6. rechts 5, links 2 Kammern. Rechtes Ovarium wird exstirpirt, links 2 Corp. lut. enthülst. 12.6. Section: Vollständiger Rủekgang. Linkes Ovarium luteopriv.

No. 23, 1910. Am 24. 5. belegt. 8. 6. rechts 3, links 2 Kammeru. Rechts 4, links 2 Corp. lut. herausgeboben. 14. 6. Section: Eier fast vollständig resorbirt. Ovarien ohne Corp. lut.

No. 25, 1910. Am 25. 5. belegt. 12. 6. rechts 4, links 2 Kammern. Rechts 4, links 1 Corp. lut. enthülst; das letzte quillt aus der Tiefe nach. 17. 6. Section: Eier in Rückbildung. Auf den Ovarien je 1 mikroskopisch erkanntes Corpus albicans.

No. 30, 1910. Am 15. 6. belegt. 30. 6. rechts 7, links 4 Kammern. Rechtes Ovarium mit 8 Corp. lat. exstirpirt. Links 3 Corp. lut. 
enthülst. 5. 7. Section: rechts 3, links 2 Kammern weitergewachsen. Im linken Ovarium ein unberührtes Corp. lut. am ligamentären Ansatz.

No. 37, 1910. Am 28. 6. belegt. 12. 7. rechts 5, links 4 Kammern. Je 5 Corp. lut. enthülst. 16. 7. Section: Kammern in Rückbildung. Ovarien luteopriv.

No. 38, 1910. Am 28. 6. belegt. 12. 7. rechts 3, links 2 Kammeru. Rechts 4, links 3 Corp. lut. enthülst. 16. 7. Section: Kammern in Rückbildung. Ovarien luteopriv.

Ich gebe eine tabellarische Uebersicht, an welchem Tage nach dem befruchtenden Coitus die Operationen gemacht wurden (Siehe Tabelle auf Seite 722):

Die weiteren bisher nicht angeführten Experimente sind für die vorliegende Frage nicht verwerthbar aus den Gründen, welche bei den einzelnen Versuchen genannt sind, wohl aber geben einige von ihnen mit anderen, oben angeführten, interessante Beiträge zur Sexualphysiologie der Kaninchen:

Coitus in graviditate: No. 43/04, 11/05, 28 und 34/06, 13, 32/07, 28, $29 / 10$.

Einseitige Insertion und Gestation wurde beobachtet: No. 6 und $28 / 04,10 / 06,13 / 07,30 / 08,5$ und 29/09, $5,16,17,34 / 10$.

Kein Coitus post partum zu erzielen: No. 50, 52, 54 und 57/04 (Festhalten und Versuch mit 3 Böcken).

Rückbildung aller Kammern vor der Operation: No. 50/09, 14/10 und $26 / 10$.

Coitus ohne dentliche Ovulation:

$$
\begin{aligned}
& \begin{array}{lllllll}
\text { No. } 6 & 06 & \text { No. } 6 & 07 & \text { No. } 1008 & \text { No. } 4209
\end{array}
\end{aligned}
$$

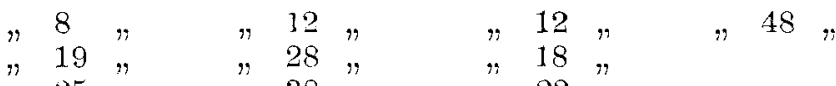

$$
\begin{aligned}
& " 25 n \quad n \quad 38, \quad " 22 n \\
& " 26, \quad \text { " } 40 \% \quad " 24 n \\
& \text { "38" " } 42, \quad " 25 " \\
& " 43, \quad " 31, \\
& " 44, \\
& " 45 "
\end{aligned}
$$

Folgende Versuche sind ungültig:

1904. No. 4 Unoperirt crepirt an Tuberculose der Lungen und des Pericards. Doppelseitige Gravidität und einseitige Ovulation.

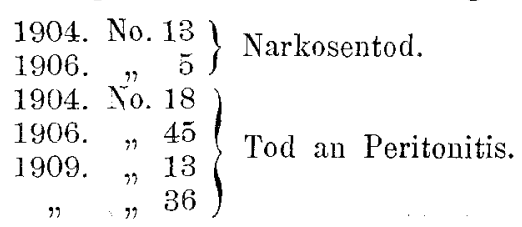

1905. No. 2, 4, 5, 6, 7, fehlender Wurf nach Ausbrennung des Corp. lut. beobachtet, aber Section nicht ausgeführt. 
722 L. Fraenkel, Neue Experimente zur Function des Corpus luteum.

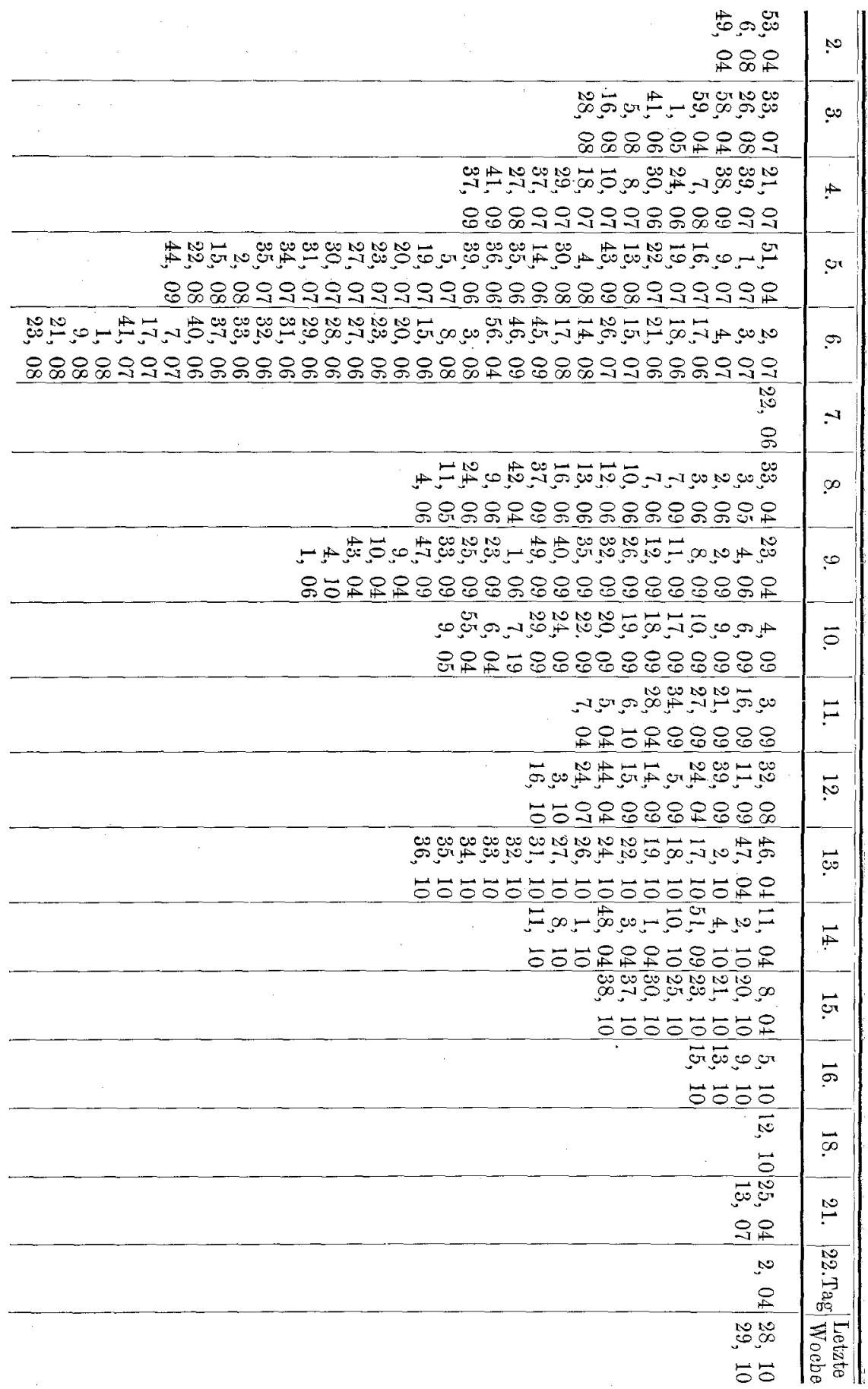


L. Fraenkel, Neue Experimente zur Function des Corpus lateum. 723

1907. No. 11 nicht operirt wegen Peritonitis. No. 25, um sichere Rückbildung zu erzielen (s. Versuche mit F. Köbner, dieses Archiv, Bd. 91, Heft 1) wurde die Uterina gleichzeitig unterbunden.

1908. No. 11 Aplasia genitalium. No. 19, fehlt die Beschreibung der Ovarien bei der Section (in meiner Abwesenheit secirt). 1909. No. 28, 31 und 1910 No. 36, Tod an Verblutung.

Alle diese Fälle, soweit operirt und zur Section gekommen, fielen im Sinne des Gesetzes aus.

Von den 277 Versuchen sind mithin gültig: 259.

Zur Beurtheilung der Function des Gesammtovariums: 29, des gelben Körpers 141, verwerthbar:

A. Vor der Eiinsertion, also meist im Laufe der ersten 6 Tage nach dem Coitus liegen 85 Versuche vor, und zwar

I. Ausschaltungen: a) der ganzen Eierstöcke: 10. Ergebnis der Section: Keine Gravidität; b) der sämmtlichen gelben Körper: 48 . Keine Gravidität.

II. Controlen (Ausschaltung eines Theils des Eierstockparenchyms, eines Theils der gelben Körper, gelegentlich nur Laparotomie oder nur Narkose) 27. Graviditäten 14.

B. Nach der Eiinsertion vom 7.-14. Tage liegen 94 Versuche vor; nämlich:

I. Ausschaltung: a) der ganzen Eierstöcke: 19; keine Gravidität; b) sämmtlicher gelber Körper: 52; keine Gravidität.

II. Controlen (wie oben) 23. Graviditäten 19.

Die anderen Versuche vertheilen sich wie folgt: 19 mal wurde in der Gravidität nach dem 14. Tage operirt und zwar nach zwei Castrationen Rückgang und nach 10 Totalausschaltungen der gelben Körper 2 mal Weiterentwickelung der Graviditäten gesehen. Ferner wurden 24 Partial- oder Totalausbrennungen der gelben Körper vorgenommen zur Erfüllung der Forderung von Sehauta, die weitere Functionsfähigkeit des Eierstockes nach dieser Operation zu erweisen. Von diesen Thieren wurden 21 wieder belegt, zum Theil in der Gravidität getödtet, zum Theil die Geburt lebender Jungen beobachtet.

Ich verfüge demnach aus den Serien von Experimenten, die im 68. Bande dieses Archivs und hier niedergelegt sind, über 141 isolirte Corpus luteum-0perationen bis zum 15. Tage. 53 Theilentfernungen mit 31 fortschreitenden Schwangerschaften, also ïber 50 pCt. 112 Totalentfernungen der gelben Körper ohne eine einzige weitergehende Gravidität. 
724 L. Fraenkel, Neue Experimente zur Function des Corpus luteum.

Damit dïrfte durch die Wucht der grossen Zahlen der von mir anfgestellte Satz erwiesen sein: Der Eierstock, speciell der gelbe Körper, steht der Ansiedlung und ersten Entwickelung des Eies vor. Halban's Postulat darf ich als erfüllt betrachten.

Zur Einflussdauer des gelben Körpers auf die Schwangerschaft des Kaninchens bin ich heute so wenig wie in der ersten Arbeit in der Lage, präcise Angaben zu machen. Magnus (9) hat auf Grund viel za kleiner Erfahrungen (8 Experimente im Ganzen) geglaubt, den 20. Tag als Grenztermin bestimmen zu können; jch hatte früher denselben Eindruck; meine neuerlichen Erfahrungen (ef. Fall No. 5 1910) scheinen Niskoubina (34), sowie Claypton und Starling (12) recht zu geben, welche den 15. Tag als Grenztermin annehmen. Es ist möglich, dass er wie der Zeitpunkt der Imprägnation, Insertion und Expulsion physiologisch schwankt.

Bezüglich der Mindestverhältnisszahl von Corpora lutea und Eikammern verfüge ich über folgende Beobachtungen: $2: 5,3: 10$, 6:11, 4:12 etc.; das bedeutet: Ein Corpus luteum ist imstande, mindestens die 3 fache Zahl von Eikammern zu protegiren.

Von Schauta und nach ihm von vielen ist der Einwand gemacht worden, meine Operation schädige durch das Ausbrennen der gelben Körper den ganzen Eierstock so erheblich, dass darauf die Sistirung der Gravidität zu beziehen ist. Aus diesem Grunde verlangte Schauta den Nachweis, dass die Ovarien nach diesem Eingriff weiter functioniren können. Diesen Beweis habe ich erbracht und möchte nun, dass ein für allemal der Einwand fällt. (Er war übrigens schon a priori durch die grosse Anzahl der Controlversuche widerlegt, u. a. Hineinbrennen von Löchern neben die unversehrten Corpora lutea und weitergehende Gravidität.) Bei einem der später gravid gewordenen Thiere (No. 28 1906) fand sich sogar nur einseitige Ovulation im vorher ausgebrannten und etwas adhärenten Ovarium, das andere vorher unberührte und normale zeigte keine Corpora lutea. Wiederholt fand sich neue Gravidität trotz intraperitonealer Adhäsionen, zweimal bei Bauchdeckeneiterung (No. 16 u. 26 1904) und einmal, trotzdem der Uterus nach Auseinanderweichen der Fascie in einem Hautbruchsack lag (No. 15 1904). Bei der Ausbrennung ist darauf zu achten, dass sie vollkommen geschieht. Man muss so lange glühen, bis alles Luteingewebe verkohlt ist. Das gelang uns leicht, nachdem wir die galvanokaustische Nadel durch einen der Grösse der Corp. lat. entsprechenden Kugelbrenner ersetzt hatten; mitunter springt der gelbe 
Körper sogleich im Ganzen heraus und bleibt am Paquelin haften. Ich habe, der Anregung von Kleinhans und Sehenk (8) folgend, bei den letzten 67 Fällen statt mit dem Thermokauter die gelben Körper kalt und stumpf ausgehülst, was sehr leicht gelingt, dabei allerdings mitunter nicht unerhebliche Blutungen aus dem Bett der gelben Körper, sonst aber keinen principiellen Untersehied in den Resultaten gesehen.

Mandl (5a), der schon in der blossen Berührung des Ovariums eine Gefahr für die Gravidität erblickte (durch die Controlversuche selbstverständlich ebenfalls ausgeschlossen), meint: Wenn bei einseitiger Ovulation (diese fand ich im Ganzen unter 272 Laparotomien $11 \mathrm{mal}: 4,11,491904,3,111905,28,36,391906,1,17$ 1907, 5 1910) nach Ausbrennung der gelben Körper der Corpus luteum-freie Eierstock unberührt bleibt, und danach in mehreren Fällen die Gravidität nicht eintritt, so liesse sich das schwer anders, als im Sinne der Corpus luteum-Theorie erklären. Auch dieser Forderung bin ich nachgekommen in den 7 Fällen: No. 34 (erste Serie) und 11, 49 1904, 3, 11 1905, 36 1906, 171907 der neuen Experimentaluntersuchung.

Damit könnte ich diese Arbeit wohl schliessen, indem ich alle Wünsche erfüllte und mit denkbar grossen Zahlen mein Gesetz belegt habe. Jede weitere Ausführung kann nur den Eindruck abschwächen. Dennoch fühle ich mich bei der Wichtigkeit der Frage und der Bedeutung der übrigen Mitarbeiter verpflichtet, auf die neue Literatur einzugehen. Es kann nicht meine Aufgabe sein, sämmtliche in den letzten 10 Jahren geäusserten, oft recht unmaassgeblichen Ansichten und Eindrücke zur Corpus luteum-Frage hier durchzugehen. Das wäre räumlich unmöglich, auch im Widerspruch stehend mit den Gepflogenheiten naturwissenschaftlich präciser Arbeit. Ich beschäftige mich also nur mit den Arbeiten, die den Versuch machen, mit streng wissenschaftlichen eigenen Forschungen diese wichtige Frage anzugehen und nachzuprüfen. Zur Untersuchung der Function des Corpus luteum sind die gleichen, aber auch von meiner Technik abweichende Methoden eingeschlagen worden, die in der Mehrzahl dahinstreben, den gelben Körper experimentell auszuschalten und die Functionen des "luteopriven" Eierstockes mit der Gesammtfunction dieses Organes zu vergleichen. Während alle anderen sich auf die uterine Function des Eierstockes beschränken, prüfen drei Autoren Rebaudi (46) und mit gleichem Resultat auch Fichera (44) und Giorgi (45) 
726 L. Fraenkel, Neue Experimente zur Function des Corpus luteum.

die Beziehung des Ovarium und Corpus lateum zu anderen Drüsen mit innerer Secretion, speciell zum Pankreas und zur Hypophysis. Rebaudi kommt zu dem Schlusse, dass durch Wegnahme der Eierstöcke, wie durch die isolirte Zerstörung sämmtlicher Corpora lutea die Langerhans'schen Zellinseln in gleicher Weise hypertrophiren. Die Methoden der übrigen Experimentatoren waren:

I. die Transplantation der Ovarien oder des Uterus

II. die Ektopirung (Verlagerung obne Schädigung des Gefässstieles).

III. die Röntgenisirung.

IV. die Paralysierung durch biochemische Gegenkörper

V. die Ausschaltungen von geschlechtlicher Erregung, Sperma, Ei.

Von kleineren technischen Abweichungen sind ausgeführt worden:

I. doppelseitige Flankenschnitte

II. Enucleation der gelben Körper.

Die Transplantation giebt unsichere Resultate, wie selbst ihr erfolgreichster Anhänger Mandl (5a) gesteht. Sehr oft heilt der Eierstock nicht ein, oder nur unter hochgradigen Veränderungen; die Gravidität, welche von dem verpflanzten Eierstock abhängt, geht bis zur Etablirung never Gefässbahnen zugrunde. Gelingt aber die Einpflanzung des Eierstocks wirklich einmal in functionell tadelloser Weise, so bildet er Corpora lutea, die, wenn die befruchteten Eier auch aus dem anderen Ovarium stammen, naturgemäss wohl imstande sind, durch innere Secretion die neuen Graviditäten zu unterhalten. Die Ektopirung (Verlagerung mit erhaltenen Gefässverbindungen) vernichtet nach Villemin (41), der sie vorschlägt, das gesammte Ovarialrindengewebe, inclusive die Follikel; grenzt also nur die eventuelle Wirkung der glande interstitielle ab. [Hier wäre auch ein Versuch am Platz, operativ die Eierstocksrinde zu entfernen. Mit dieser "Decortication" bin ich am Kaninchen nicht zustande gekommen 1)]. Ebenso ist die Dosirung der Röntgenstrahlen, bezüglich des Effectes auf das Eierstocksgewebe unsicher und nicht streng eklektisch. (ef. die Arbeit von Specht (11) aus Neisser's und meinem Laboratorium). Bei der Verwendung der Antikörper konnte Lichwitz (5) und ich (1c) so wenig wie Skrobansky (4b)

1) Eine aussichtsreiche Methodik ist vielleicht die künstlich erzeugte Parabiose, um das vicariirende Eintreten des einen Thieres für die Gravidität des anderen zu pürfen [nach Sauerbracb und Heyde (10)]. 
zu sicheren Resultaten kommen. Die experimentelle Ausschaltung der unter $\mathrm{V}$ angeführten bei der Befruchtung mitwirkenden Factoren soll die Verwundung des weiblichen Organismus und der Ovarien umgehen (Ancel, Bouin, Loeb). Der Flankenschnitt (Niskoubina u. A.) ist blutreicher, länger dauernd, das Auffinden der Ovarien planloser, dadurch die Gefahr ihrer Läsion grösser, die Mitbeobachtung des Uterus ungenügend gegenüber der medianen Laparotomie, bei welcher der Uterus durchaus nicht berührt werden muss. Endlich ist die stumpfe Herausnahme der gelben Körper [Kleinhans und Schenk (8)] leicht auszuführen, doch kommt es aus dem Bett des gelben Körpers mitunter zu vicht unerheblichen Nachblutungen, die einen Einwand gegen die Resultate zur Fọlge haben können (z. B. ist die Zahl der Rückbildungeu bei den Controltieren von K. u. Sch. gegenüber meinen Erfahrungen viel zu gross). Dieses zur allgemeinen Methodik und nun sollen die einzelnen Arbeiten berücksichtigt werden.

Eine der wichtigsten Arbeiten, welche auf dem ganzen Gebiete geschrieben worden ist, weil sie mit neuer Fragestellung und experimenteller Anordnung arbeitet, diejenige ron $\mathrm{M}$ andl habe ich in Wien selbst vor dem Verfasser und der dortigen gynäcologischen Gesellschaft in meinem Vortrage einer Kritik unterworfen. Ich habe gegen die angewandte Technik, die nicht genügend präcisen Angaben über gelbe Körper und Eikammern und die Deutung der mikroskopischen Abbildungen schwerwiegende Bedenken vorgebracht, die der Autor in den dann folgenden längeren Ausführungen weder durch Demonstration der hierher gehörigen Präparate, noch durch andere Argumente zu widerlegen versucht hat. Ich muss also constatiren, dass dureh die sehr interessanten und geistvollen Experimente Mandl's die Corpus Juteum-Theorie nicht erschüttert worden ist. Den ersten Teil meiner Versuche, die den Einfluss des Gesammt-Ovariums auf die Ansiedlung der Schwangerschaft beweisen, erkennt $\mathrm{Mandl}$, auch Halban (2), vollkommen an. Nur Skrobansky (4) hat im Gegensatz zu ihnen in derselben Diskussion höchst verblüffende Mittheilungen gemacht. Nach ihm hatte die Castration niemals, die isolirte Entfernung der Corpora lutea stets die Schwangerschaftsunterbrechung zur Folge. Er glaubt, dass die innere Secretion des Corpus luteum dazu diene, die schädliche Einwirkung des Gesammtovariums auf die Gravidität zu paralysiren. Nachdem ich nach 51 Castrationen stets Unterbrechung der Sehwangerschaft sah, darf ich über Skrobansky's Behauptung zur Tages- 
ordnung übergehen. Alle anderen Autoren haben den Einfluss des Gesammtovariums auf die Gravidität anerkannt, in neuerer Zeit Lane Claypton und Starling (12) von neuem experimentell bestätigt.

Die Arbeit von Kleinhans und Schenk (8), die 1904 in Breslau vorgetragen und mehrere Jahre später publicirt wurde, ist nicht geeignet und wohl auch nicht geschrieben, um das Corpus luteum-Gesetz zu prüfen, sondern den Grenztag der Wirksamkeit zu ermitteln. Die Autoren hoben mit der Pinzette die gelben Körper heraus und sahen vom 9. Tage nach dem befruchtenden Coitus ab fortschreitende Graviditäten. Dabei ist zweifellos zunächst ein Rechenfehler unterlaufen; ich kann kein einziges Experiment vom 9. sondern nur solche vom 11., 13. und 15. Tage finden. Aber selbst in dieser Einschränkung sind die Experimente so wenig vollgültig, wie die Mandl's. Es fehlen nämlich sehr oft Angaben über die Zahl der Kammern, die den entfernten Corpora lutea entsprechen, sowie über den Sectionsbefund der Ovarien. Diese Angaben sind aber von der grössten Wichtigkeit. Wiederholt habe ich beobachtet, dass weit mehr gelbe Körper da waren als Kammern, cf. z. B. No. 17 und 35 1910, ferner genügten einige wenige Corpora lutea um die mehrfache Zahl von Kammern zu protegiren; endlich und am wichtigsten: Ich habe mich im laufe der vielen Jahre überzengt, dass es ausserordentlich schwer ist, aller Corpora lntea mit Sicherheit habhaft zu werden, und unmöglich, am Schlusse der 0peration zu behaupten, alle Corpora lutea seien entfernt. Wenn man durch einen ausreichenden Schnitt ein langgestieltes 0varium mühelos an die oberfläche gebracht hat und bei tiefer Narkose des Thieres in aller Ruhe betrachtet, ohne die zuführenden Gefässe zu comprimiren, dann stechen die Corpora lutea durch ihre rothe Farbe so intensiv hervor, dass man es gar nicht für möglich halten sollte, eines zu übersehen. Und doch ist nichts leichter als das. Sie kommen mitunter mit einer minimalen Spitze, dicht an der ligamentären Insertion des Eierstockes an die Oberfläche, oder verbergen sich im Innern des 0variums. Sie sitzen ferner polypös gestielt, vom Eierstock entfermt, z. B. fast ganz auf dem Ligamentum ovarii, und, sobald die Blutzufuhr nur im geringsten stockt, heben sie sich auch für das geübte Auge nicht mehr genügend vom Eierstock oder Ligament ab. Ich glaubte eine Zeit lang, um Thiere zu sparen, dieselbe Operation an einem Thiere in verschiedenen 
Zeiten mehrere Male machen zu dürfen, und nach der Entfernung der gelben Körper ans dem Nichtwerfen anf die Richtigkeit des Gesetzes zu schliessen. Eine ganz falsche Versuchsanordnung. Diese Fälle (No. 2 und $4-7$ 1905. No. 12, 14-17, $10-22,26,27,29-32,34-41$ 1904. No. 81905 und No. 28 1906) sind für die Functionsprüfung des Corpus luteum ungiltig, die 0peration und ihr Protokoll beweist absolut nichts für unsere Frage; erst in Verbindung mit einer sehr sorgfältigen Section zeigt es sich, ab man ein Ausfallsexperiment über die Function des Corpus luteum angestellt hat, oder einen Controlversuch. Ja selbst der makroskopische Befund der aufgeschnittenen Ovarien bei der Section kann nicht in allen Fällen entscheiden; man sieht oft weissliche Kugeln, die man für Corpora lutea halten möchte, aber mikroskopisch nicht verificiren kann und umgekehrt. Ich führe als charakteristisch in dieser Beziehung die Protokolle 28 1904. 15 1907. 14 1903. 5, 19, 23, 28, 38, 40, 44 47 1909. 4, 17, 20, 24, 25, 301910 an. Ich muss also fordern, dass jeder Experimentator zur Corpus luteum-Physiologie folgende Bedingungen erfülle:

1. Er muss angeben, wie viele, wie beschaffene und situirte Eikammern er bei der 0peration fand, und wielviel gelbe Körper er aus jedem Ovarium entfernte.

2. Er muss die 0varien bei der Section makroskopisch, im geringsten Zweifelfalle auch mikroskopisch untersuchen, beschreiben, anch rorweisen. Diese Postulate sind ron Mandl und Kleinhans-Schenk nicht erfüllt.

In neuester Zeit hat Niskoubina (34) meine Experimente mit gleicher Technik, nur Flankenschnitt statt medianer Laparotomie, wiederholt und die ganze Corpus luteum-Frage einer ausführlichen Erörterung unterzogen; sie bestätigt die Abhängigkoit der Ei-Insertion und -Entwicklung vom gelben Körper, dessen Einfluss sie beim Kaninchen auf den 14.-15. Tag nach dem Coitus begrenzt. Die mikroskopische Untersuchung von Ovarien, deren Corpora lutea thermokaustisch zerstört waren, sowie Controlversuche belehrten sie, dass das Ovarium durch diesen Eingriff anatomisch und functionell nicht beeinflusst werde. Sie geht die Literatur durch, widerlegt alle Einwände, wirft für den unten zu besprechenden Fall von Essen-Möller die Frage auf, ob nicht ein Beobachtungsfehler irgendwelcher Art unterlaufen ist, und schliesst sich meinen Ergebnissen auch in den Detailsfragen an. 
Sehr interessante Versuche und neue Gesichtspunkte zur Abgrenzung der Function von gelbem Körper und Glande interstitielle liegen von Ancel und Bouin (33) vor. Die Autoren unterscheiden die Säuger in solche mit spontaner und solche durch die geschlechtliche Annäherung bewirkter Ovulation. Die letzteren haben nur das "Corps jaune gestatif", während die ersteren dieses und "Corps jaunes périodiques" produciren. Zur ersteren Gruppe gehören Weib, diverse Affen, Hündin, Stute, Schwein, Kuh; zur zweiten Kaninchen, Meerschweinchen, Katze. Nun behaupten sie, dass die Thiere mit nicht spontaner Ovulation, denen das periodische Corpus luteum fehlt, an dessen Stelle die Glande interstitielle besitzen, welche wieder den spontan und periodisch ovulirenden Thierspecies abgeht ${ }^{1}$ ). Beide - Glande interstitielle und Corps jaune périodique - seien homologe Bildungen, welche den weiblichen Sexualcharakter durch innere Secretion aufrecht erhalten. Das Corps jaune gestatif dagegen sei eine allen Säugethieren gemeinsame Drüse und mit der Function begabt, die ich kennen gelehrt habe.

Da meinen Experimenten gegenüber eingewendet worden sei, dass eine zu grosse Verwundung des Thieres, speciell der Ovarien hierbei vorgenommen und der mögliche Einfluss des befruchteten Eies selbst (Halban) nicht genügend ausgeschlossen werde, so haben sie neue experimentelle Wege eingeschlagen:

1. Sie verwendeten virginelle weibliche Kaninchen, die bei ihrer ersten Brunst den Bock zum ersten Mal erblickten. Auf diese Weise ist der Einfluss früherer Corpora lutea oder Graviditäten auszuschliessen.

2. Sie machten die Befruchtung durch den Coitus unmöglich, indem sie dem Männchen das Vas deferens einige Monate zuvor unterbanden. Sie erzielten dadurch bei der Häsin das Corps jaune gestatif ohne befruchtetes Ei.

3. Sie sprengten reife Follikel brünstiger Weibchen künstlich und erzeugten so die Corpora lutea. Wenn man 2 oder 3 Follikel in der Zeit sexueller Erregung mit feiner Nadel oder Scheere öffnet, so wandeln sich nach ihren Beobachtungen die anderen reifen Graaf'schen Bläschen spontan in Corpora lutea, auch am anderen Eierstock. Solche Corpora lutea verhalten sich morphologisch und functionell wie die echten Corps jaunes gestatifs; ihr Einfluss

1) Diese Angaben werden zur Zeit in meinem Laboratorium einer Nachprüfung unterzogen. 
auf den Uterus ist ganz der gleiche, wie ich ihn s. Z. beschrieb und hält ebenso wie die aufsteigende Entwicklung des gelben Körpers selbst bis zum 15. Tage an. Da das Corpus luteum der einzige in den Organismus eingeführte neue Factor sei, so könne nur dieses die prägraviden Veränderungen des Uterus bewirken, welche die Fixation des Eies gestatten. Das Gleiche gilt von den ersten Schwangerschaftsveränderungen der Mamma, auch sie werden unter Ausschluss des Eies ganz allein vom gelben Körper bewirkt.

Wichtige Versuche sind aus Amerika berichtet worden. Loeb (42) zeigte, dass die experimentelle Erzeugung einer Decidua bei Meerschweinchen oder Kaninchen gelingt, wenn man 2 bis 9 Tage nach der Ovulation Schnitte durch den Uterus macht, die seine Continuität trennen. Copulation ist dazu nicht nöthig, auch bei der durch Tubenunterbindung verhinderten Einwanderung des Eies gelingt das Experiment. Vorherige Exstirpation der Ovarien oder Vernichtung der Corpora lutea hindert die Deciduabildung (die nur an den Schnittstellen sich findet). Demnach geht der Reiz zur Deciduabildung nach der Entstehung des Corpus luteum nicht vom Ei, sondern vom Ovarium aus und wird durch innere Secretion vermittelt, denn auch in vorher (z. B. subcutan) transplantirten Uterusstücken bildet sich die Decidua. Locb verlegt den Sitz der inneren Secretion, welche diese hochinteressanten Veränderungen bewirkt, in das Corpus luteum.

Ich komme jetzt zu dem viel citirten, objectiv und gut beschriebenen Falle von Elis Essen-Völler (13). Nach Castration einer Frau in den ersten Wochen der Graviditat sah er ausgetragene Schwangerschaft. Wenn der Fall genau so liegt, wie der Verfasser vermuthet, d. h. keinerlei luteinhaltiges Eierstockgewebe im Körper zurückgeblieben ist, bezugsweise wenn ähnliche Fälle wiederholt mitgetheilt werden, so ist für den Menschen die Einflussdauer des Corpus luteum zu reduciren. Dennoch möchte ich wegen der Möglichkeit individueller Schwankungen die von mir empfohlene Vorsicht bei der Ovariotomie in graviditate nicht ausser Acht zu lassen rathen und davor warnen, diesen einen Fall zu früh zu verallgemeinern. Von meinen Experimenten musste ich, wie oben ausgeführt, eine grössere Anzahl streichen, bei denen ich mich mit der klinischen Beobachtung nach der Operation begnügte. Die vielfache Erfahrung lehrt, dass erst die Section mit mikroskopischer Untersuchung zu einem sicheren Schluss über das Experiment berechtigt. Ein noch so zuverlässig beschriebener, ausschliesslich 
klinisch beobachteter Fall steht zweifellos an Werth weit hinter den exakten Experimenten zurück. Bucura (26) verlangt für den Nachweis der stattgehabten experimentellen Castration mit vollem Recht die Zerlegung des Stumpfes in lückenloser Serie, weil diese allein beweist, dass keinerlei Eierstocksgewebe zurückgelassen worden war. Die Castration wird beim Weibe so rorgenommen, dass im Lig. ovarii proprium eine Abbindung stattfindet; dieses Band ist oft noch mit Eierstocksrindengewebe überzogen; aus dem Zurückbleiben von solchem erklären sich die nicht seltenen Fälle von angeblich regelmässiger Menstruation nach Castration. In der Sitzung der gynäkologischen Gesellschaft zu Chicago vom 20. November 1909 sind Beobachtungen mitgetheilt worden, welche mit diesen Ausführungen vollkommen übereinstimmen. Riess entfernte bei einer Laparotomie Theile des rechten Ovariums, bei einer zweiten Operation die ganzen rechten Adnexe. die er vorzeigt. Es besteht durchaus der Eindruck, dass die Castration eine vollständige war. Wie gross war sein Erstaunen, als er bei einer 3. Laparotomie an der rechten Uteruskante einen Körper fand, der aus Ovarium bestand, ja sogar ein Corpus luteum enthielt. Riess hält solche Fälle nicht für selten. In der Discussion theilten Frankenthal und Watkins je einen ähnlichen Fall mit. Webster and Barrett gaben der Operationsmethode die Schuld. Bei der Zusammenschnürung des Stieles bleiben sehr oft Reste von Eierstocksgewebe zurück, welche sich zu umfangreichen und gut functionirenden Organen umbilden; es sei sogar wahrscheinlich, dass in solchen Ovarialresten nicht nur Eierstocksstroma, sondern sogar Follikel neu gebildet werden können.

Soweit die Literatur äber die Beziehungen von Corpus luteum und Gravidität von Mensch und Kaninchen. Bei anderen Säugern wurden meines Wissens Versuche ausser durch Loeb nur von P. Mulon (47) ebenfalls am Meerschweinchen angestellt, die im gleichen Sinne ausgefallen sind.

Durch die Arbeiten der letzten Jahre tritt immer mehr hervor, dass sämmtliche Drüsen mit innerer Secretion in antagonistischer oder synergetischer Beziehung stehen (cf. mein Sammelreferat in Zeitschrift für Geburtshilfe und Gynäkologie, Bd. 64). Wenn das richtig ist, so muss die Abhängigkeit der Gravidität vom Corpus luteum kein völlig isolirtes Phänomen sein, sondern kann durch Unterstützung gewisser Drüsen gefördert, durch Conträrfunction anderer gestört, im Nothfall endlich durch Suppleation dritter übernommen 
L. Fraenkel, Neue Experinente zur Function des Corpus lateum. 733

werden. Hier liegen noch dunkle Beziehungen vor, die vielleicht manche Einzelbeobachtung erklären können, welche mit meinen Hunderten von Experimenten in scheinbarem Widerspruch stehen. Im Eierstock selbst fanden wir in den letzten Jahren noch andere Gewebe, welche einer inneren Secretion fähig scheinen (Glande interstitielle, Theca interna der ungesprungenen Follikel). Diese, an Constanz und Bedeutung zweifellos hinter dem Corpus luteum zurücktretend (ef. die demnächst aus meinem Laboratorium erscheinende Arbeit von A. Schäffer), dürfen immerhin in Rechnung gezogen werden. Späteren Forschungen muss es vorbehalten bleiben, die Wirkungen aller dieser innerlich secernirenden Drüsen zu erkennen, von einander abzugrenzen oder die gemeinsamen Functionen herauszufinden. In diesem Sinne ist vielleicht das Corpus Juteum-Gesetz eines weiteren Ausbaues fähig, andererseits die Bedeutung des gelben Körpers mit seinen Beziehungen zum Uterus nicht erschöptt').

Mit dem zweiten Theil des Corpus luteum-Gesetzes, wonach der gelbe Körper dem gesammten genitalen Turgor der Generationsjahre und der cyklischen Ueberernährung (Abscheidung der Menstruation) vorsteht, habe ich mich in den letzten Jahren experimentell aus mehrfachen Gründen nicht beschäftigt. Das Thiermaterial war durch die Absicht, die Zahlen für Theil I bedeutend zu vermehren, vollkommen in Anspruch genommen. Auch sind Experimente bezüglich der Gravidiät viel exacter und objectiver anzustellen, wie solche über die Uterusernährung. Ueber das Vorhandensein oder Fehlen einer Gravidität ist nicht zu disputiren, wohl aber über einen Grad von Turgor oder Atrophie, der noch dazu individuell und zeitlich ausserordentlich schwankt. Zudem fehlt das nach aussen tretende Signal, die Menstruation, den Thieren, mit denen ich arbeitete, ganz.

1) P. Mulon (35) zieht eine Paraliele zwischen der Nebenniere und dem Corpus luteum. Die Zellen beider Drüsen entstehen aus dem Koelomepithel und machen die gleichen Umwandlungen durch, welche in der Nebennierenrinde in der Weise vor sich gehen, dass in der äussersten Schicht die Zellen mit Fetttropfen, in der zweiten solche mit osmophilen Körperchen, in der dritten mit pigmentirten Granulationen sich finden. Die osmophilen Granula sind in gelben Körpern and Nebennieren morphologisch- und histo-chemisch identisch. Die Nebennierenzellen wandeln sich aus Fetttröpfchenzellen in pigmentirte um durch Abgabe des Fettes und ebenso die Luteinzellen. Der gelbe Körper der Schwangerschaft ist also functionell eine Art temporärer Nebennierenrinde. 
734 L. Fraenkel, Neue Experimente zur Function des Corpus luteum.

Wenn die Wirkung des Corpus luteum anf die Ansiedlung des Eies allgemein anerkannt sein wird, dann werden sich die Forscher mit neuem Eifer anf die grösseren allgemeinen Beziehungen zum Uterus werfen. Diese sind nur die logische Folge der ersten Hälfte des Gesetzes. Ich habe schon mehrfach ausgeführt, dass das Corpus luteum, sit venia verbo, ja nicht wissen kann, ob es einem Ei zur Nistung verhelfen wird. Es kann nur eine einzige Function dieser Art haben, und diese ist die prägravide Vorbereitung des Uterus, die Herbeiführung der Veränderungen des Prämenstruum; das erscheint logisch - naturwissenschaftlichem Denken selbstverständlich; aber ohne Follikel keine Corpora lutea, es können also sehr wohl durch die luteinoide Umwandlung des reifenden Follikels die ersten Uterusveränderungen ausgelöst werden. Ich sehe demnach bei Vorhandensein sprungfertiger Follikel keine Möglichkeit, die Richtigkeit meiner Ansicht exakt zu beweisen, ausser durch Experimente ähnlicher Art, wie für die Gravidität. Solche können aber nur bei Tieren angestellt werden, die eine echte Menstruation haben, weil durch die einmalige Wegnahme der Luteinkörper der Uterus keiner schweren Atrophie verfällt, sondern mit Bildung neuer corpora lutea sofort wieder heranwächst. Es wird bei dieser Versuchsanordnung nur der ganz besondere Turgor fehlen, bei dessen Abschätzung schon sehr viel Subjektives dazu kommt. Aber selbst die Abscheidung der Menstruation ist kein so objectiv sicheres Merkmal der Uterus- und Corpus luteum-Function, wie die Gravidität. Menstruation ist uterine Blutung, und eine solehe kann nach jedem operativen und psychischen Trauma zustande kommen. Auf der anderen Seite ist vielleicht die Wellenbewegung in der Blutdruckcurve des weiblichen Organismus gelegentlich auch ohne Ovarien im Stande, cyklische Blutungen aus dem Uterus zu bewirken. [Vergl. Gellhorn (14)].

Es werden sich also gegen derartige Experimente Einwände machen lassen, wenn nicht wieder eine imponirend grosse Zahl von Versuchen vorliegt. Dazu müsste man eine Expedition zur Ausführung grosser Serien von Affen-Experimenten unternehmen, oder an Menschen selber in grosser Zahl bei gelegentlichen Operationen die gelben Körper vernichten. Ich habe in meiner ersten Arbeit über 9 derartige Fälle berichtet und alsbald die Anstellung weiterer, aus verständlichen Gründen für den Privatmann nicht unbedenklichen Beobachtungen abgelehnt. Ich gebe gern zu, diese 
9 Versuche für sich allein genügten nicht, als man den ersten Theil des Gesetzes noch nicht für bewiesen hielt, um den zweiten Theil vollkommen zu stützen. Nachdem nun Theil I durch ganz andere Zahlen und eindeutige Resultate belegt ist, sollte man diese Versuche an Krankenhausmaterial aufnehmen. An dem Erfolge zweifle ich nicht. Hier möchte ich nur im Hinblick auf die nach meinen ersten Corpus luteum-Entfernungen beobachtete Suppressio mensium und den dagegen erhobenen Einwand bemerken, dass das Ausbleiben der Menstruation nach einer gynäkologischen Operation (mit Ausnahme der Entfernung der Uterusschleimhant) m. E. zu den Seltenheiten gehört. Wenn man also immer wieder nach Entfernung des Corpus luteum die nächste Menstruation sich erheblich verspäten sieht, so dürfte kaum eine andere Erklärung als die der Abhängigkeit vom Corpus luteum mögljch sein. Dieselbe logische Schlussfolgerung ziehen Lin den thal (15), F ü th (16), Jardry (36), Villemin (41), Campbell (17), E. Kehrer (18) und andere. Die oben angeführten $\nabla$ ersuche von Ancel mit Bouin und Loeb, welche die Eiinsertion ausschliessen und ohne Zerstörung des Corpus luteum seine Effecte auf den Uterus studiren, sprechen gleichfalls ganz eindeutig im gleichen Sinne.

Die Versuche Bucura's (26) sind in keiner Weise geeignet, dem zu widersprechen. Letzterer hat 3 Experimente gegen den zweiten Teil des Corpus luteum-Gesetzes verwenden wollen:

I. Einem castrirten Kaninchen werden die Eierstöcke eines graviden Meerschweinchens eingepflanzt; nach 58 Tagen wird das Thier getötet, der Uterus ist atrophisch, in den eingeheilten Ovarien wird ein wohlerhaltenes Corpus luteum constatirt. Follikel fehlen. - Bucura wird wohl nicht im Ernst erwarten, dass ein einziges sporadisches Meerschweinchen Corpus luteum die Castrationsatrophie des Kaninchen-Uterus aufhalten muss.

II. Unvollkommene Castration zweier Kaninchen. Im Stumpf finden sich bei der Section nach über 60 Tagen Ovarialgewebe mit Follikeln, aber ohne Corpora lutea. Keine Uterusatrophie. Daraus schliesst Bucura, dass nicht das Corpus luteum der Uterusernährung vorstehen kann. - Auch dieser Schluss ist hinfällig, da aus den Follikeln sich stets neue Corpora lutea bilden und die Section vielleicht gerade in die Phase zwischen zwei Ovulationen fiel. Für die Richtigkeit dieser Ueberlegung spricht ein Experiment von Bucura selbst, und ein weiteres von Marshall 
736 L. Fraenkel, Nene Experimente zur Function des Corpus luteum.

und Jolly (24). Bucura (26) setzte einem castrirten Kaninchen die Ovarien eines jungen, nicht graviden Meerschweinchens ein. Nach 51 Tagen ist der Uterus nicht atrophisch, das eine Ovarium ist zum Theil zu erkennen, enthält reichlich unveränderte Follikel und ein wohlerhaltenes Corpus luteum. Marshall und Jolly fanden in einem einzigen Falle von Castration den Uterus nicht atrophisch und hier bei der Section eine kleine Partie Ovarialgewebe mit ganz frisch entwickelten Corpora lutea im Stumpf.

Ausser Bucura baben sich nur noch vier Autoren in experimenteller Arbeit mit dem II. Theil des Corpus luteum-Gesetzes beschäftigt, Villemin (41), Rebaudi (46), Regaud und Dubreuil (50). Villemin hat eine umfängliche Monographie über die Function der gelben Körper herausgegeben. Er beschäftigt sich nicht mit dem I. Teil des Gesetzes; die Frage, ob der gelbe Körper derUterusernährung vorsteht, versucht er mittels einer in dem Capitel über die allgemeine Methodik erwähnten, von der meinigen abweichenden Versuchsanordnung zu lösen: Verwendung von Röntgenstrahlen und Verlagerung des mit seinen Gefässen und Nerven in Verbindung bleibenden Eierstockes. Er kommt dabei zu der Behauptung, dass es auf jedem der beiden Wege gelingt, die Corpora lutea auszuschalten und die glande interstitielle isolirt zu erbalten. Da nunmehr der Uterus degenerirte, so schliesst er sich meiner Auffassung über die Function des Corpus luteum vollkommen an. Trotz dieser Zustimmung muss ich mit der gleichen Kritik, wie gegenüber Bucura, seinen Versuchen die Beweiskraft absprechen, weil Villemin mittels beider Methoden nicht nur die Corpora lutea, sondern nach seinen eigenen Angaben den gesammten Follikelapparat mit zerstört, also nur erweisen kann, dass es nicht die glande interstitielle ist, die der Uterusernährung vorsteht. Weiterhin beschäftigt sich Villemin mit den zeitlichen Beziehungen zwisehen Ovulation und Menstruation, auf die ich weiter unten zurückkommen werde, und endlich mit der experimentellen Prüfung der Secretionsproducte des Corpus luteum. Eine grosse Anzahl physiologischer und pathologischer örtlicher und allgemeiner Erseheinungen, des Eintritts und Ausbleibens, der Qualität und Quantität der Menstruation führt er auf ein Zuviel oder Zuwenig dieses Secretes zurück, Folgerungen, die vielleicht heute noch ein wenig verfrüht sind.

Villemin hat meine Theorie ferner dahin erweitert, dass aueh 
L. Fraenkel, Neue Experimente zur Function des Corpns luteum.

die Brunst durch das Corpus luteum bewirkt sei; hier sind ihm in den Histologen Regaud und Dubreuil scharfe Gegner erwachsen. Mit den Beziehungen des Corpus luteum zur Brunst habe ich mich niemals beschäftigt; schon aus dem Grunde, weil der Begriff der Brunst bis heute anatomisch nicht definirt ist. Die allgemein giltige physiologische Definition „Brunst ist die Zeit, zu der das Weibchen zur Kohabitation geneigt ist", habe ich acceptirt, ohne sie je wissenschaftlich zu verwerthen oder gar zu folgern, dass diese Neigung des Weibchens die Folge der Tätigkeit des Corp. lut. sei. (NB.: Wenn die physiologische Definition richtig ist, so kann man nicht das Erscheinen der Menstruation bei der Frau mit der tierischen Brunst identificiren.)

Für meine Theorie ist es völlig gleichgiltig und thatsächlich bis heute nicht entschieden, ob die so definirte Brunst das primäre und der Follikelsprung secundär ist. Aus meinen eigenen Beobachtungen (1 a) hatte ich den Eindruck, dass unter dem Einfluss des Coitus der Follikelsprung befördert wird. R. und D. zeigen in sehr verdienstrollen Experimenten, unter welchen Bedingungen und in welcher Weise die Brunst entsteht bezw. verhindert werden kann, und dass, wie ich es bereits annahm, das Corp. lut. sich erst nach der durch die Brunst hervorgerufenen Begattung bildet. D. und R. gehen aber weiter und meinen, dass auch die cyclische Vitalitätsvermehrung des Uterus nicht die Folge des Corp. lut. sei. Sie haben bei denselben 8 Kaninchen zu verschiedenen Zeiten der Sexualtätigkeit immer wieder durch Bauchschnitt die Ovarien und den Uterus betrachtet und constatirt, dass zur Zeit, wo frische Corp. lut. da waren, der Uterus stets congestionirt, geröthet, vergrössert (Verhältniss von $3: 1$ ) gefunden wurde. Trotzdem sei es unwahrscheinlich, dass die "modifications prégravidiques" von den Corpora lutea ausgehen, weil die klassische Curve ibrer Entwicklung. chronologisch gegen die uterinen Veränderungen im Rückstande sei, eine Ansicht, mit welcher diese Histologen unter ihren Fachgenossen allein dastehen. (cf. Ancel-Bouin, Niskoubina, Villemin, Kreis, Sobotta u. A.)

Dubreuil und Regaud meinen übrigens, dass ich die in einigen Fällen gefundene schwere Uterusatrophie bei fehlenden Corpora lutea mit der physiologischen puerperalen Atrophie verwechsle. Vor diesem Missgeschick dürfte mich eine anf diesem Gebiet nicht ganz kleine Erfahrung (auch bei nicht puerperalen 
738 L. Fraenkel, Neue Experimente zur Function des Corpus luteum.

Tieren) bewahrt haben. Die puerperale Involution erreicht unter normalen Verhältnissen niemals die enormen Grade von Gebärmutter. Verkümmerung, welche ich beschrieb, ausser dann, wenn eben nach dem Wurf die neue Brunst, Ovulation, Corpusluteum-Bildung nicht eintritt. Eine Hyperinvolution post partum auf primär physiologischer Basis, z. B. durch Lactation bedingt, habe ich in meinen Versuchen ausdrücklich ausgeschlossen.

Im Capitel über die allgemeine Methodik erwähnte ich bereits die Versuche von Rebaudi Die Lectüre seiner ausführlichen Arbeiten zeigt, dass es sich um äusserst werthvolle Beobachtungen handelt. Nachdem er die Physiologie und Histologie des Pankreas und seines vornehmlich der inneren Secretion dienenden Antheiles, der sogenannten Langerhans'schen Zellhaufen beim Kaninchen genau geschildert hat, berichtet er über 2 Serien von Experimenten: In der ersten werden die ganzen Ovarien entfernt, und die gerannten Zellhaufen bei der nach 5, 15, 25, 35, 60, 90, 240 und 360 Tagen vorgenommenen Section untersucht. Man fand dann jedesmal in der blutüberfüllten Bauchspeicheldrüse eine evidente Hypertrophie, Hyperplasie und Hyperämie der Langerhans'schen Inseln und starke Anschwellungen ihrer Zellen durch fuchsinophile Granulationen. Genau dieselbe Wirkung beobachtete er in der zweiten Serie bei isolirter Entfernung der gelben Körper. Der einzige Unterschied war, dass die Wirkung in der ersten Reihe vom 15.-35. Tage ab am stärksten war, während in der zweiten Reihe schon vom 20. Tage ab der Effect etwas nachliess. Wenn er Ovarial- bezugsweise Lutein-Extract gleichzeitig injicirte, fielen die Veränderungen im Pankreas bedeutend geringer aus. Die beigegebenen Bilder illustriren die detaillirte histologische Beschreibung. Er schliesst: "Dieses beweist klar, dass das Corpus luteum als Organ innerer Secretion zu betrachten ist und als vornehmstes, wenn nicht einziges Element innerer Function des Eierstockes. "Ich habe Rebaudi's Angaben gelegentlich geprüft, sie scheinen mir richtig. Es dürfte sich um eine aussichtsreiche biologische Forschungsmethode handeln für die Beziehungen der Drüsen mit innerer Secretion untereinander und zur Differenzirung des Einflusses der gelben Körper auf den Organismus gegenüber dem GesammtOvarium 1 ).

1) Sirtori (32) fand, dass in der normalen Schwangerschaft die Langerhans'schen Inseln zunehmend verkümmern. 
Giorgi (45) hat in der Hypophysis nach Zerstörung der Corpora lutea gleichfalls histologische Beweise starker functioneller Hyperactivität gefunden.

Eine logische Folgerung der Corpus luteum-Theorie II. Theil ist, dass die Ovulation der Menstruation zeitlich vorangeht. Hier komme ich auf ein viel bearbeitetes und umstrittenes Feld. Meiner wiederholt ausgesprochenen Ansicht nach geht die Ovulation der zu ihr gehörigen Menstruation etwa 1-2 Wochen voraus. Dass dies richtig sei, möchte man schon a priori erwarten bei Betrachtung des zeitlichen Verhältnisses der analogen Vorgänge von Befruchtung und Einistung: Ein Follikel platzt, verwandelt sich in das Corpus luteum, das Ei wird befruchtet und wandert durch die Tube. Es ist nachgewiesen, dass in diesem Zeitraum Veränderungen im Uterus sich ausbilden, welche die Nidation ermöglichen und mit dem Prämenstruum functionell und anatomisch [Hitsehmann-Adler (25), Nyhoff (19)] identisch sind. Unterbleibt die Befruchtung oder Ansiedlung des Eies, so scheidet sich die Menstruation ab. Kann eine functionelle Abhängigkeit eigentlich selbstverständlicher sein? Obwohl eine Reihe von Autoren die gleiche Abhängigkeit und zeitliche Folge behaupten, und nach meinem Eindruck ihre Zahl immer grösser wird, stehen doch noch hauptsächlich 2 Gründe der allgemeinen Anerkennung entgegen.

I. Die zweifellos nicht absolute Regelmässigkeit dieses Zeitablaufes.

II. Die grosse Autorität und Erfahrung Leopold's, der in verschiedenen Arbeiten immer wieder dafür eingetreten ist, dass keine festen zeitlichen Beziehungen zwischen Ovulation und Menstruation bestehen.

Leopold arbeitet an einem grossen Material, das sich wesentlich aus exstirpirten kranken Genitalien zusammensetzt, rein anatomisch, d. h. am Präparat und selbstverständlich dadurch ohne Möglichkeit die nächstfolgende Menstruation zu beobachten. Ich bearbeitete ein wenig kleineres Material mit ganz gesunden oder nur verlagerten Organen, welche direct an der lebenden Frau inspicirt aber belassen wurden, also hauptsächlich physiologisch. Seit 7 Jahren werden bei allen Laparotomien mit gesunden inneren Genitalien, extragenitalen Tumoren, Osteomalacie, der uncomplicirten Appendicitis-Operation, Prolaps- und Retroflexions-Operationen die vorausgegangene und der Operation folgende und bezw. zweitfolgende Menstruationen notirt, beziehungsweise beobachtet, die 
Ovarien vorgezogen, genau inspicirt, der Befund protocolirt. Ueber die ersten 18 Beobachtungen hat Hergesell (21) aus meiner Klinik berichtet. Seitdem liegen weitere 85 Operationsbefunde vor, die alle von mehreren geübten Beobachtern gemeinsam begutachtet wurden. Wie meine Tabelle zeigt, habe ich Fälle, wie die sämmtlichen aus Leopold-Ravano's (20) letzter Arbeit, herausgehoben, denn weder Myomovarien, noch durch peritoneale Verwachsungen beeinflusste Genitalien konnte ich als zur Entscheidung geeignet ansehen. Operationen bei unregelmässig blutenden Frauen und Salpingo-Oophoritiden habe ich überhaupt nicht verwerthet. — Jede von beiden Methoden hat ihre Fehlerquellen und Unzulänglichkeiten; die Le opold's, ausser dem Grundfehler der kranken Genitalien, dass der Termin der vorangegangenen Menstruation oft und der der folgenden stets fehlt, und dass bei der Altersbestimmung des Corpus luteum Subjectivität nicht ganz auszuschliessen ist. Meine Methode, die Inspection der Ovarien an der Lebenden, kann nur die an die Oberfläche tretenden Corpora lutea constatiren, und deren Alter nicht mikroskopisch bestimmen; findet sich hier kein Zeichen von Ovulation, so ist das noch kein Beweis, dass kein Corpus luteum vorhanden ist. Aber sie hat den Vortheil, die Corpora lutea gelegentlich in dem ganzen Turgor der Vitalität zu sehen, und sowohl die vorausgegangene, wie die folgenden Menstruationen zu beobachten. Da nun die Altersbestimmung nicht mehr ganz frischer Corpora lutea recht schwierig ist (genau auf den Tag sie anzugeben, halte ich für unmöglich), so habe jch aus meinen 85 Fällen nur diejenigen herausgenommen und der Berechnung zu Grunde gelegt, welche a) z. Z., dicht vor oder nach der Operation regulär und unter Abwesenheit aller anderen pathologischen Blutungen menstruirten; b) ein hochrothes, haselnussgrosses, weiches, sukkulentes und prominentes, bei leiser Berührung oder spontan blutendes Corpus luteum aufwiesen. Ich glaube, dass die von uns selbst beobachtete Menstruation ebenso sicher constatirt ist, wie der so beschriebene gelbe Körper als vollkommen frisch bezeichnet werden kann. Dagegen habe ich auf die Einbeziehung aller irregulär blutenden Frauen verzichtet, wie auf die Altersbestimmung von härteren oder mehr entfärbten Corpora lutea, ebenso habe ich es vermieden, grosse, dünnwandige oder während der Operation geborstene Follikel als reif zu bezeichnen und entsprechend zu verwerthen. Eine Anzahl Daten fehlen uns, wenige infolge Defecten in den Krankengeschichten, meist darum, weil wir in der ersten Zeit verabsäumten, 


\begin{tabular}{|c|c|c|c|c|c|}
\hline 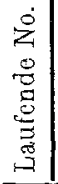 & Name. & $\begin{array}{l}\text { Typus der } \\
\text { Men- } \\
\text { struation }\end{array}$ & $\begin{array}{c}\text { Eintritt } \\
\text { der letaten } \\
\text { Men- } \\
\text { struation }\end{array}$ & $\begin{array}{l}\text { Befund der Ovarien } \\
\text { bei Operation }\end{array}$ & $\begin{array}{c}\text { Erste } \\
\text { Menstruation } \\
\text { nach der } \\
\text { Operation }\end{array}$ \\
\hline 1 & $\begin{array}{l}\text { Frau G. } \\
\text { Prv. } 1901 . \\
\text { No. } 256 .\end{array}$ & $\begin{array}{c}2-3 \text { wöchentlich } \\
\text { sehr stark. }\end{array}$ & 27. 2. & $\begin{array}{l}\text { 19. 3. 01. Am linken Ovarium ein } \\
\text { ganz frisches Corp. lut. }\end{array}$ & Regelmässig. \\
\hline 2 & $\begin{array}{l}\text { Frau K. } \\
1903\end{array}$ & $\begin{array}{l}4 \text { wöchentlich } \\
2-3 \text { Tage. }\end{array}$ & 8. 11 . & $\begin{array}{l}\text { 11. 11. 03. Kein sprungfertiger Folli- } \\
\text { kel, kein Corp. lut. }\end{array}$ & $25 .-27.12$ \\
\hline 3 & $\begin{array}{l}\text { Frl. lir } \\
\text { (Virgó) }\end{array}$ & $\begin{array}{l}4 \text { wöchentlich } \\
6-8 \text { Tage. }\end{array}$ & 4. 1. & $\begin{array}{l}\text { 20. 1. 04. Ganz friscbes Corpus } \\
\text { luteum. }\end{array}$ & Regelmässig. \\
\hline 4 & $\begin{array}{l}\text { Prv. } 1904 . \\
\text { Frau H. } \\
1904 .\end{array}$ & $\begin{array}{c}2-3 \text { wöchenlich } \\
4 \text { Tage. }\end{array}$ & 20.1 . & 3. 2. 04. Kein Corp. lut. & $\begin{array}{l}\text { 15.-19.3., (er- } \\
\text { wartet am 24.2.) }\end{array}$ \\
\hline 5 & $\begin{array}{l}\text { Frau K. } \\
1904 .\end{array}$ & Regulär. & 3. 6. & $\begin{array}{l}\text { 13. 6. 04. Kein Corp. lut., ein nahezu } \\
\text { sprungfertiger Woilikel zu sehen. }\end{array}$ & 29. 6. bis 3.7 . \\
\hline 6 & Frau W. & $\begin{array}{l}\text { Sonst regulär, seit } \\
\text { April alle } 10 \text { Tage, } \\
3-4 \text { Tage anhalt. }\end{array}$ & 8. 6. & $\begin{array}{l}\text { 30. 6. 04. Allerfrischestes Corp. } \\
\text { jut. bei Berührung spritzend (noch } \\
\text { nicht geronnen). }\end{array}$ & 5. 7. \\
\hline 7 & $\begin{array}{c}\text { Frau } H . \\
1904\end{array}$ & & 15. 10 . & $\begin{array}{l}\text { 2. 11. } 1904 \text {. Fast absolut frisches } \\
\text { Corp. Iut., } 1-3 \text { tg., haselnussgross, } \\
\text { tief braun, rothblaulich. }\end{array}$ & - \\
\hline 8 & $\begin{array}{l}\text { Frau G. } \\
\text { Prv. } 1905 .\end{array}$ & Regulär. & 12. 2. & $\begin{array}{l}23.2 .05 . \text { Ganz frisches Corp. } \\
\text { luteum. }\end{array}$ & - \\
\hline 9 & $\begin{array}{l}\text { Frau M. } \\
\text { Pry. 1905. }\end{array}$ & $\begin{array}{l}\text { Seit } 2 \text { Jahren } \\
\text { irregulär. }\end{array}$ & 6. 10 . & $\begin{array}{l}\text { 30. 10. 05. Im linken Ovarium fast } \\
\text { walnussgrosser, schon etwas weieber, } \\
\text { verfarbter Follikel. }\end{array}$ & 1.- -4.11 . \\
\hline 10 & $\begin{array}{c}\text { Frau S. } \\
\text { Plsl. } 1906 .\end{array}$ & Regulär. & 14. 1. & $\begin{array}{l}\text { 24. 1. } 06 \text {. Reineklaudengrosses Cor- } \\
\text { pus luteum. }\end{array}$ & -- \\
\hline 11 & $\begin{array}{l}\text { Frau K. } \\
\text { Pbl. } 1906 .\end{array}$ & Regulär. & 18. 1. & $\begin{array}{l}\text { 3. 2. 06. Kein frisches Corp. lut., } \\
\text { Kein Follikel an der Oberfläche. }\end{array}$ & - \\
\hline 12 & $\begin{array}{l}\text { Frau A. } \\
\text { Prv. } 1906 .\end{array}$ & $\begin{array}{c}4-6 \text { wöchentlich } \\
4-5 \text { Tage. }\end{array}$ & 21. 6 . & $\begin{array}{l}\text { 11. 7. } 06, \text { Ganz frisches Corpus } \\
\text { luteum. }\end{array}$ & 13. 7. \\
\hline 13 & \begin{tabular}{|l} 
Fri. P. \\
Prv. 1906.
\end{tabular} & $\begin{array}{c}3-4 \text { wöchentlich } \\
5-6 \text { Tage. }\end{array}$ & - & $\begin{array}{l}\text { 11. 7. } 06 \text {. Ganz frisehes Corpus } \\
\text { Iuteum. }\end{array}$ & 13. 7. \\
\hline 14 & $\begin{array}{l}\text { Frau S. } \\
\text { Prv. 1906. }\end{array}$ & $\begin{array}{c}3-4 \text { wöchentlich } \\
8 \text { Tage. }\end{array}$ & 9.7. & $\begin{array}{l}\text { 2. 8. 06. Kleines, frisehes Corp. } \\
\text { Iuteum. }\end{array}$ & 3. 8. \\
\hline 15 & $\begin{array}{l}\text { Frak N. } \\
\text { Prv. 1907. }\end{array}$ & $\begin{array}{l}\text { In den letzten } \\
\text { Jahren } \\
\text { 6-9 wöchentlich } \\
3-7 \text { Tage. }\end{array}$ & 6. 1. & $\begin{array}{l}\text { 18. 1. } 07 . \text { Kein Corp. Iut., kein siche- } \\
\text { rer sprungfertiger Follikel. }\end{array}$ & $\begin{array}{c}\text { In der Llinisehen } \\
\text { Beobachtung } \\
\text { keine Men- } \\
\text { struation. }\end{array}$ \\
\hline 16 & $\begin{array}{l}\text { Frau Soh. } \\
\text { Prv. } 1907 .\end{array}$ & Regulär. & 13. 1 . & $\begin{array}{l}\text { 21. 1. 07. Ohne frische Ovulation an } \\
\text { der Oberfläche der Ovarien. }\end{array}$ & do. \\
\hline 17 & $\begin{array}{l}\text { Fall } \\
\text { Dr. } K .\end{array}$ & $?$ & $\begin{array}{l}\text { Soeben } \\
\text { beendet. }\end{array}$ & $\begin{array}{l}\text { 9. 3. 07. Ein mindestens } 10 \text { Tage } \\
\text { altes Corp. lut. }\end{array}$ & do. \\
\hline 18 & $\begin{array}{l}\text { Frau M. } \\
\text { Prv. } 1907 .\end{array}$ & Regulär. & & $\begin{array}{l}\text { 27. 4.07. Frisches Corpus Iu- } \\
\text { teum. }\end{array}$ & do. \\
\hline 19 & $\begin{array}{l}\text { Frau P. } \\
\text { Pril 1907. }\end{array}$ & $\begin{array}{l}2-3 \text { wöchentlich } \\
8 \text { Tage sehr stark. }\end{array}$ & 20. 6 . & $\begin{array}{l}\text { 10. 7. 07. Nichts von Ovulation zu } \\
\text { seben. }\end{array}$ & do. \\
\hline 20 & $\begin{array}{l}\text { Frau N. } \\
\text { Plel. } 1908 .\end{array}$ & Regulärr. & & $\begin{array}{l}\text { 15. 1, os. Keine Spur von Ovulation } \\
\text { zu sehen. }\end{array}$ & do. \\
\hline 21 & \begin{tabular}{|l} 
Frl. (. \\
Pry. 1908.
\end{tabular} & Regulär. & 23. 1. & $\begin{array}{l}\text { 17. 2. 08. Ganz frisches Corpus } \\
\text { luteum. }\end{array}$ & $\begin{array}{l}\text { 20. 2. (einen } \\
\text { Tag verfrüht). }\end{array}$ \\
\hline 22 & Frau S. & Regulär. & $\begin{array}{l}\text { 15. 2. Soeb. } \\
\text { beendet. }\end{array}$ & $\begin{array}{l}\text { 21. 2, } 08 \text {. Kein Zeiohen friseber Ovu- } \\
\text { lation. }\end{array}$ & $\begin{array}{l}\text { In der Klinik } \\
\text { keine Menstruat. }\end{array}$ \\
\hline
\end{tabular}


742 L. Fraenkel, Neue Experimente zur Function des Corpus Iuteum.

\begin{tabular}{|c|c|c|c|c|c|}
\hline 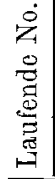 & $\mathrm{Name}$ & $\begin{array}{l}\text { Typus der } \\
\text { Men- } \\
\text { struation }\end{array}$ & $\begin{array}{c}\text { Eintritt } \\
\text { der letzten } \\
\text { Men- } \\
\text { struation }\end{array}$ & $\begin{array}{l}\text { Befund der Ovarien } \\
\text { bei Operation }\end{array}$ & $\begin{array}{l}\text { Erste } \\
\text { Menstruation } \\
\text { nach der } \\
\text { Operation }\end{array}$ \\
\hline 23 & $\begin{array}{l}\text { Frau Sch. } \\
\text { Pkl. } 1908 .\end{array}$ & $\begin{array}{l}4 \text { wöchentlich } \\
5 \text { Tage. }\end{array}$ & 9. 2 . & 14. 3. Kein Zeichen frischer Ovulation. & - \\
\hline 24 & $\begin{array}{l}\text { Frau F. } \\
\text { Pkl. } 1908 .\end{array}$ & $3-31 / 2$ wöchentl. & 20.3. & $\begin{array}{l}\text { 6. 4. 08. Zweigleicheganz frische } \\
\text { Corpora lutea. }\end{array}$ & - \\
\hline 25 & $\begin{array}{l}\text { Frau G. } \\
1908 .\end{array}$ & $\begin{array}{l}\text { 4wöchentlich } \\
3 \text { Tage. }\end{array}$ & 28.3. & 6. 4. 08. Keine Ovulation zu sehen. & 一 \\
\hline 26 & $\begin{array}{l}\text { Frau K. } \\
\text { Prv. } 1908 .\end{array}$ & Regulär. & 30. 4 . & $\begin{array}{l}\text { 14. 5. 08. Frisches Corpus 1u- } \\
\text { teum. }\end{array}$ & 21.-25. 5 \\
\hline 27 & $\begin{array}{l}\text { Frau Sch. } \\
\text { Pkl. } 1908 .\end{array}$ & $\begin{array}{c}\text { Irregulär, ca. } \\
\text { 3wchtl., 2-9Tge. }\end{array}$ & 26. 4. & $\begin{array}{l}\text { 19. 5, 08. Kirschgrosses, ziem- } \\
\text { lich frisches Corpus luteum. }\end{array}$ & $22 .-25.5$ \\
\hline 28 & $\begin{array}{l}\text { Frau Dr. A. } \\
\text { Prv. } 1908 .\end{array}$ & $\begin{array}{l}\text { Irregulär, } 14 \text { Tage } \\
\text { bis } 3 \text { Wochen, } \\
8 \text { Tage. }\end{array}$ & 1. 5. & $\begin{array}{l}\text { 22. 5. 08. Kirschgrosses, ziem- } \\
\text { lich frisches Corpus luteum. }\end{array}$ & 24. 5 . \\
\hline 29 & $\begin{array}{l}\text { Frau F. } \\
\text { Pkl. } 1908 .\end{array}$ & $\begin{array}{c}3 \text { wöchentlich } \\
3-5 \text { Tage. }\end{array}$ & 7. 10 . & 21. 10. 08. Keine frische Ovulation. & 13. 11. \\
\hline 30 & $\begin{array}{l}\text { Frl. St. } \\
\text { Prv. } 1908 .\end{array}$ & $\begin{array}{l}14 \text { Tage } \\
5 \text { Tage. }\end{array}$ & & $\begin{array}{l}\text { 6. 11. 08. Frisch geplatztes Cor- } \\
\text { pus luteum. }\end{array}$ & 11. 11 . \\
\hline 31 & $\begin{array}{l}\text { Frl. T. } \\
\text { Pkl. } 1909 .\end{array}$ & $\begin{array}{c}3-4 \text { wöchentlich } \\
1 \text { Tag. }\end{array}$ & $\begin{array}{l}\text { Mitte Dec. } \\
1908 .\end{array}$ & $\begin{array}{l}\text { 13. 1. 09. Ziemlich frisches Cor- } \\
\text { pus luteum. }\end{array}$ & 15.--17. 1 \\
\hline 32 & $\begin{array}{l}\text { Frau B. } \\
\text { Prv. } 1909 .\end{array}$ & 31/2 wöehentlich. & Seit 11. 1. & 16. 1. 09 . Kein Corp. ]ut. zu sehen. & $\begin{array}{l}\text { Geringe Blutung } \\
\text { am } 24 . \text { u. } 25.1 .\end{array}$ \\
\hline 33 & $\begin{array}{l}\text { Frl. H. } \\
\text { Pkl. } 1909 .\end{array}$ & $\begin{array}{c}\text { Seit } 3 \text { Monaten } \\
2-3 \text { wöchentl. } \\
3-5 \text { Tage, sonst } \\
\text { regulär } 4 \text { Wochen } \\
3 \text { Tage. }\end{array}$ & 15. 1. & $\begin{array}{l}\text { 10.2.09. Ein hochrothes, frisches } \\
\text { Corp. lut. + ein älteres Corp. } \\
\text { luteum. }\end{array}$ & $\begin{array}{l}\text { In der Klinik bis } \\
\text { zum 1. 3. keine } \\
\text { Menstruation. }\end{array}$ \\
\hline 34 & $\begin{array}{l}\text { Frau Seh. } \\
\text { Prv. } 1909 .\end{array}$ & Regulär. & 31. 1. & $\begin{array}{l}\text { 22. 2. 09. Grosses, nicht mehr } \\
\text { ganz frisches Corp. lut. }\end{array}$ & 25. 2 . \\
\hline 35 & $\begin{array}{l}\text { Frau N. } \\
\text { Pkl. } 1909 .\end{array}$ & Regulär. & 1. & $\begin{array}{l}\text { 2. 3. } 09 \text {. Keine Zeichen bevorstehender } \\
\text { oder stattgehabter Ovulation. }\end{array}$ & $\begin{array}{l}\text { In der Klinik } \\
\text { keine } \\
\text { Menstruation. }\end{array}$ \\
\hline 36 & $\begin{array}{l}\text { Frau B. } \\
\text { Prv. } 1909 .\end{array}$ & $\begin{array}{l}\text { 4wöchentlich } \\
8 \text { Tage. }\end{array}$ & 18. 3. & $\begin{array}{l}\text { 26. 3. 09. Ziemlich sprungfertiger } \\
\text { Follikel; springt durch Druck bei } \\
\text { der Operation. }\end{array}$ & $\begin{array}{l}\text { Menstruat } \\
\text { do. }\end{array}$ \\
\hline 37 & $\begin{array}{l}\text { Frau N. } \\
\text { Pkl. } 1909 .\end{array}$ & $\begin{array}{l}4 \text { wöchentlich } \\
2 \text { Tage. }\end{array}$ & 4 & $\begin{array}{l}\text { 3. 4. 09. Etwas verblasstes, gel- } \\
\text { bes, kirschgrosses, ziemlich } \\
\text { festes Corp. Iut. }\end{array}$ & 4. 4 . \\
\hline 38 & $\begin{array}{l}\text { Frau U. } \\
\text { Pkl. } 1909 .\end{array}$ & $\begin{array}{l}4 \text { wöchentlich } \\
3 \text { Tage. }\end{array}$ & 3. 4. & $\begin{array}{l}\text { 17. 4. 09. Kein Corp. lut oder sprung- } \\
\text { fertiger Follikel. }\end{array}$ & (M. ?) $19 .-21.4$ \\
\hline 39 & $\begin{array}{l}\text { Frl. H. } \\
\text { (Virgo) }\end{array}$ & Regulär. & 25. 3. & 20.4. 09. Aelteres Corp. lut. & $21 .-23.4$ \\
\hline 40 & $\begin{array}{l}\text { Prv. } 1909 . \\
\text { Frau M. } \\
\text { Pkl. } 1909 .\end{array}$ & $\begin{array}{l}\text { Seit } 8 \text { Wochen } \\
\text { irregul. Blutungn. } \\
\text { Früher stets } \\
\text { regelmässig. }\end{array}$ & 28. 6. & $\begin{array}{l}\text { 30. 6. 09. Altes entfärbtes Corp. } \\
\text { lut. in Rü̈ckbildung. Keine } \\
\text { frische Ovulation. }\end{array}$ & $\begin{array}{l}\text { In der Klinik } \\
\text { keine } \\
\text { Menstruation. }\end{array}$ \\
\hline 41 & $\begin{array}{l}\text { Frau Sch. } \\
\text { Prv. } 1909 .\end{array}$ & $\begin{array}{c}\text { Seit } 1 \text { Jahre } \\
6 \text { wöchtl. } 3 \text { Tage, } \\
\text { sonst } 4 \text { wöchentl. } \\
8 \text { Tage. }\end{array}$ & 30.6 . & $\begin{array}{l}\text { 9. 7. 09. Ziemlich frisches Corp. } \\
\text { luteum. }\end{array}$ & do. \\
\hline
\end{tabular}




\begin{tabular}{|c|c|c|c|c|c|}
\hline 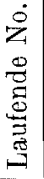 & $\mathrm{Name}$ & $\begin{array}{l}\text { Typus der } \\
\text { Men- } \\
\text { struation }\end{array}$ & $\begin{array}{c}\text { Eintritt } \\
\text { der letzten } \\
\text { Men- } \\
\text { struation }\end{array}$ & $\begin{array}{l}\text { Befund der Ovarien } \\
\text { bei Operation }\end{array}$ & $\begin{array}{l}\text { Erste } \\
\text { Menstruation } \\
\text { nach der } \\
\text { Operation }\end{array}$ \\
\hline 42 & $\begin{array}{l}\text { Frau B. } \\
\text { Prv. 1909. }\end{array}$ & $\begin{array}{l}\text { Irregulär, mit- } \\
\text { unter nur } 8 \text { bis }\end{array}$ & 24.6 . & $\begin{array}{l}\text { 15. 7. } 09 . \text { Frisches, haselnuss- } \\
\text { grosses Corp. lut. }\end{array}$ & - \\
\hline 43 & $\begin{array}{l}\text { Frau A. } \\
\text { Pkl. 1909. }\end{array}$ & $\begin{array}{l}\text { Irregulär. } \\
\text { In. }\end{array}$ & 24. 6 . & $\begin{array}{l}\text { 17. 7. } 09 . \text { Wenig prominentes, ziem- } \\
\text { lich entfärbtes, ziemlich hartes } \\
\text { Corp. lut. }\end{array}$ & Nach 2 Monaten. \\
\hline 44 & $\begin{array}{l}\text { Frl. G. } \\
\text { (Virgo) } \\
1909 .\end{array}$ & $\begin{array}{l}\text { Regulär } \\
3 \text { wöchentlich } \\
8 \text { Tage. }\end{array}$ & 2. 7 . & $\begin{array}{l}\text { 17. 7. } 09 \text {. Walnussgrosses, prominen- } \\
\text { tes, blaurothes, dünnwandiges } \\
\text { Corp. lut. }\end{array}$ & $20 .-23.7$ \\
\hline 45 & $\begin{array}{l}\text { Frau M. } \\
\text { Prv. } 1909 .\end{array}$ & $\begin{array}{l}3 \text { wöchentlich } \\
8 \text { Tage. }\end{array}$ & 30. 6 . & $\begin{array}{l}\text { 20. 7. 09. Ziemlich frisches, } \\
\text { kirschkerngrosses, prominen- } \\
\text { tes Corp. lut. }\end{array}$ & - \\
\hline 46 & $\begin{array}{l}\text { Frau A. } \\
\text { Pkl. 1909. }\end{array}$ & $\begin{array}{l}4 \text { wöchentlich } \\
2 \text { Tage. }\end{array}$ & 10. 7. & $\begin{array}{l}\text { 24. 7. 09. Frisches Corp. lut. } \\
\text { gelb, weich, nicht sehr prominent. }\end{array}$ & $25 .-27.7$. \\
\hline 47 & $\begin{array}{l}\text { Frau G. } \\
\text { Pkl. } 1909 .\end{array}$ & ca. 3 wöchentlich. & 12. 7. & $\begin{array}{l}\text { 29. 7. 09. Ganz frisches, bei } \\
\text { Berührung blutendes. Corpus }\end{array}$ & $6 .-9.8$. \\
\hline 48 & $\begin{array}{l}\text { Frau G. } \\
\text { Prv. 1909. }\end{array}$ & Regulär. & 15. 7. & $\begin{array}{l}\text { 4. 8. 09. Ziemlich frisches Corp. } \\
\text { luteum. }\end{array}$ & $\begin{array}{l}\text { In der Klinitk (bis } \\
22.8 . \text { ) keine }\end{array}$ \\
\hline 49 & $\begin{array}{l}\text { Fran B. } \\
\text { (Virgo) } \\
\text { Prv. 1909. }\end{array}$ & $\begin{array}{c}2-3 \text { wöchentliche } \\
\text { Menorrhagien. }\end{array}$ & 8. 7. & $\begin{array}{l}\text { 21. 8. 09. Frisches Corp. luteum } \\
\text { beiderseits. }\end{array}$ & $24 .-27.8$ \\
\hline 50 & $\begin{array}{l}\text { Frau R. } \\
\text { Prv. } 1909 .\end{array}$ & Regulär. & 4. 8. & $\begin{array}{l}\text { 25. 8. 09. Nicht ganz frisches } \\
\text { Corp. luteum. }\end{array}$ & $26 .-31.8$ \\
\hline 51 & $\begin{array}{l}\text { Frau V. } \\
\text { Pkl. } 1909 .\end{array}$ & $\begin{array}{c}2-3 \text { wöchentlich } \\
8 \text { Tage. }\end{array}$ & 17. 7. & $\begin{array}{l}\text { 25. 8. 09. Ganz frisches Corpus lut. } \\
\text { mit Blut. }\end{array}$ & 30. 8.-2. 9 . \\
\hline 52 & $\begin{array}{l}\text { Frau Sch. } \\
\text { Pkl. } 1909 .\end{array}$ & $\begin{array}{l}\text { Früher } 4 \text { wöchentl. } \\
8 \text { Tage, in letzter } \\
\text { Zeit anticep. } \\
\text { bürzer }\end{array}$ & 7. 10 . & $\begin{array}{l}\text { 20. 10. 09. Sprungfertiger, sehr grosser } \\
\text { Follikel lutenoid? }\end{array}$ & 25. 11. \\
\hline 53 & $\begin{array}{l}\text { Frau K. } \\
\text { Pkl. } 1909 .\end{array}$ & $\begin{array}{l}3-4 \text { wöchentlich } \\
5 \text { Tage. }\end{array}$ & & $\begin{array}{l}\text { 4. 11. 09. Grosses, nicht ganz } \\
\text { frisches Corp. lut. }\end{array}$ & 11.-14. 11 \\
\hline 54 & $\begin{array}{l}\text { Frl. G. } \\
\text { (Virgo) } \\
\text { Prv. 1909. }\end{array}$ & Regulär. & 16. 10. & $\begin{array}{l}\text { 4. 11. 09. Grosses, ganz frisches } \\
\text { Corp. luteum. }\end{array}$ & 8.-9. 11 . \\
\hline 55 & $\begin{array}{l}\text { Frau Th. } \\
\text { Pkl. } 1909 .\end{array}$ & $\begin{array}{l}4 \text { wöchentlich } \\
1-2 \text { Tage. }\end{array}$ & & 20. 11. 09. Keine Ovulation. & $\begin{array}{l}\text { In der Klinik keine } \\
\text { Menstruation. }\end{array}$ \\
\hline 56 & $\begin{array}{l}\text { Frau S. } \\
\text { Pkl. } 1909 .\end{array}$ & $\begin{array}{l}4 \text { wöchentlich } \\
5 \text { Tage. }\end{array}$ & ca. 30.10. & $\begin{array}{l}\text { 20. 11. 09. Rechtes Ovarium grösser, } \\
\text { äusserl. kein Follikel oder Corp. lut. }\end{array}$ & 21. 11 \\
\hline 57 & $\begin{array}{l}\text { Frau E. } \\
\text { Pkl. } 1909 . \\
\text { Frau K. }\end{array}$ & Regulär. & $\begin{array}{l}\text { Seit } \\
3 \text { Tagen. } \\
29.1\end{array}$ & $\begin{array}{l}\text { 6. 1. 10. Keine Zeichen frischer Ovu- } \\
\text { lation. } \\
\text { 12. 2. 10. Am linken Ovarium ein }\end{array}$ & Am 12. 2. \\
\hline & & & & $\begin{array}{l}\text { sehr verdünnter haselnussgrosser } \\
\text { Follikel. }\end{array}$ & \\
\hline 5 & $\begin{array}{l}\text { Frau P. } \\
\text { Pkl. } 1910 .\end{array}$ & $\begin{array}{l}4 \text { wöchentlich } \\
3 \text { Tage. }\end{array}$ & 18. 2. & $\begin{array}{l}\text { 3. 3. 10. Linkes Ovarium enthält ein } \\
\text { haselnussgrosses, dunkelrothes, s u c- } \\
\text { cul entes Corpus l u teum. }\end{array}$ & 28. 4 . \\
\hline 60 & $\begin{array}{l}\text { Frau F. } \\
\text { Pkl. } 1910 .\end{array}$ & Regulär. & 9. 4. & $\begin{array}{l}\text { 4. } 5.10 . \text { Haselnussgrosses, ockergel- } \\
\text { bes, etwas trockenes Corpus luteum. } \\
\text { Centrum in bindegewebiger Organi- } \\
\text { sation ohne Blut. (Castration.) }\end{array}$ & - \\
\hline
\end{tabular}


744 L. Fraenkel, Neue Experimente zur Function des Corpus luteum.

\begin{tabular}{|c|c|c|c|c|c|}
\hline 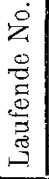 & $\mathrm{Name}$ & $\begin{array}{l}\text { Typus der } \\
\text { Men- } \\
\text { struation }\end{array}$ & $\mid \begin{array}{c}\text { Eintritt } \\
\text { der letzten } \\
\text { Men- } \\
\text { struation }\end{array}$ & $\begin{array}{l}\text { Befund der Ovarien } \\
\text { bei Operation }\end{array}$ & $\begin{array}{l}\text { Erste } \\
\text { Menstruation } \\
\text { nach der } \\
\text { Operation }\end{array}$ \\
\hline 61 & \begin{tabular}{|l|} 
Frau K. \\
Pkl. 1910.
\end{tabular} & Regulär. & 15. 3. & $\begin{array}{l}\text { 8. 4. 10. In beiden Ovarien je ein } \\
\text { erbsengrosses älteres Corp. lut. }\end{array}$ & 16.-18. 5 \\
\hline 62 & Frl. G. & Regulär. & 12. 5 . & $\begin{array}{l}\text { 31. } 5.10 \text {. Kein Corp. lut. Am linken } \\
\text { Ovarium haselnussgrosse, dünn- } \\
\text { wandige, intra operationem geplatzte } \\
\text { Cyste. }\end{array}$ & $2 .-5.6$ \\
\hline 63 & $\begin{array}{c}\text { Frl. V. } \\
\text { Prv. } 1910 .\end{array}$ & $\begin{array}{l}4 \text { wöchentlich } \\
5 \text { tägig. }\end{array}$ & & $\begin{array}{l}\text { 9. } 6.10 \text {. Ovarien ohne jede Zeichen } \\
\text { von Ovulation. }\end{array}$ & 28. 6.--2. 7 . \\
\hline 64 & $\begin{array}{c}\text { Frau D. } \\
\text { Prv: } 1910 .\end{array}$ & 4 wöchentlich. & 30.6 . & $\begin{array}{l}\text { 7. } 70 . \text { Keinerlei Zeichen von } \\
\text { Ovulation. }\end{array}$ & $4,-7.8$ \\
\hline 65 & $\begin{array}{l}\text { Frau Sch. } \\
\text { Pkl. } 1910 .\end{array}$ & Regulär. & 13. 6. & $\begin{array}{l}\text { 7. 7. 10. Ininkes Ovarium enthält ein } \\
\text { etwas trockenes, braunes Corp. lut. }\end{array}$ & $7 .-10.7$ \\
\hline 66 & $\begin{array}{l}\text { Frl. R. } \\
\text { Pkl. 1910. } \\
\text { (Virgo) }\end{array}$ & $\begin{array}{l}\text { Irregulär, zu } \\
\text { selten. }\end{array}$ & 23. 7. & $\begin{array}{l}\text { 28. } 7.10 . \text { Linkes Ovarium olne, } \\
\text { rechtes mit älterem Corp. lut. }\end{array}$ & $3 .-6.9$. \\
\hline 67 & $\begin{array}{l}\text { Frau H. } \\
\text { PkI. } 1910 .\end{array}$ & $\begin{array}{l}4 \text { wöchentlich } \\
3 \text { Tage. }\end{array}$ & 3. 8. & $\begin{array}{l}\text { 16. 8. 10. Am rechten Ovarium ein } \\
\text { haselnussgrosser, fast sprungfertiger } \\
\text { Follikel. }\end{array}$ & - \\
\hline 68 & Frau K. & 4 wöchentlich. & 1. 8. & $\begin{array}{l}\text { 20. 8. } 10 \text {. Rechtes Ovarium enthält } \\
\text { ein kleinkirsehgrosses, prominentes, } \\
\text { braunrotes Gebilde. Zweifelhaft, ob } \\
\text { Follikel mit lutenoider Wandum- } \\
\text { bildung oder Corp. lut. } \\
\text { variotomien. }\end{array}$ & - \\
\hline 69 & Frl. P. & Regulär? & 18. 10 . & $\begin{array}{l}\text { 31. 10. } 03 \text {. Ein halb- und viertel- } \\
\text { sprungfertiger Follikel werden beide } \\
\text { entleert. }\end{array}$ & $\begin{array}{l}\text { 3. 11. nachher } \\
\text { Amenorrhoe bis } \\
\text { Februar. }\end{array}$ \\
\hline 70 & Frau A. & $\begin{array}{l}\text { 4wöchentlich } \\
\text { 3-4 Tage. }\end{array}$ & & - & - \\
\hline 71 & $\begin{array}{l}\text { Frau W. } \\
\text { Prv. } 1905\end{array}$ & Regulär. & ca. 22.12 & $\begin{array}{l}\text { 4. 1. 05. Corpus luteum etwas } \\
\text { klein, doch ziemlich friseh. }\end{array}$ & - \\
\hline 72 & $\begin{array}{l}\text { Frl. K. } \\
\text { (Virgo) } \\
\text { Prv. 1909. }\end{array}$ & 19. 12. & 28.4 & $\begin{array}{l}\text { 8. 5. 09. Ganz frisches, grosses } \\
\text { Corpus luteum. }\end{array}$ & 16.-19. 5 \\
\hline 73 & $\begin{array}{l}\text { Frau B. } \\
\text { Prv. 1910. }\end{array}$ & 4 wöchentlich. & 14. 5. & $\begin{array}{l}\text { 17. 6. 10. Nicht mehr ganz frisches } \\
\text { Corp. lut. (Ovariotomia sinistra. } \\
\text { Dermoid.) }\end{array}$ & $17 .-21.6$. \\
\hline 74 & $\begin{array}{l}\text { Frau H. } \\
\text { Plkl. } 1910 .\end{array}$ & $\begin{array}{l}4 \text { wöchentlich } \\
2-3 \text { Tage. }\end{array}$ & 13. 6. & $\begin{array}{l}\text { 25. 6. } 10 . \text { Keine Zeichen frischer } \\
\text { Ovulation. }\end{array}$ & $28 .-31.7$ \\
\hline & & & & Adhäsionen. & \\
\hline 75 & $\begin{array}{l}\text { Frau F. } \\
\text { Prv. 1904. } \\
\text { Frau F. } \\
\text { Prv. 1909. }\end{array}$ & $\begin{array}{l}4 \text { wöchentlich } \\
3 \text { Tage. }\end{array}$ & $\begin{array}{l}25.6 . \\
31.3 .\end{array}$ & $\begin{array}{l}\text { 29. 6. 04. Ziemlich frisches Corp. } \\
\text { luteum. } \\
\text { 8. 4. 09. Kein Corpus luteum. }\end{array}$ & 24.- -26.4 \\
\hline 77 & $\begin{array}{l}\text { Frau H. } \\
\text { Prv. 1910. }\end{array}$ & Regulär. & 19. 12. & $\begin{array}{l}\text { 12. 1. 10. Corpus luteum, etwas } \\
\text { trocken, braungelb. }\end{array}$ & $\begin{array}{c}14.1 . \\
\text { dann } 24 .-28.2 .\end{array}$ \\
\hline
\end{tabular}




\begin{tabular}{|c|c|c|c|c|c|}
\hline 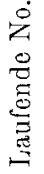 & $\mathrm{Name}$ & $\begin{array}{c}\text { Typus der } \\
\text { Men- } \\
\text { struation }\end{array}$ & $\mid \begin{array}{c}\text { Eintritt } \\
\text { der Ietzten } \\
\text { Men- } \\
\text { struation }\end{array}$ & $\begin{array}{c}\text { Befund der Ovarien } \\
\text { bei Operation }\end{array}$ & $\begin{array}{c}\text { Erste } \\
\text { Menstruation } \\
\text { nach der } \\
\text { Operation }\end{array}$ \\
\hline
\end{tabular}

\section{Uterusexstirpation. a) bei Myom.}

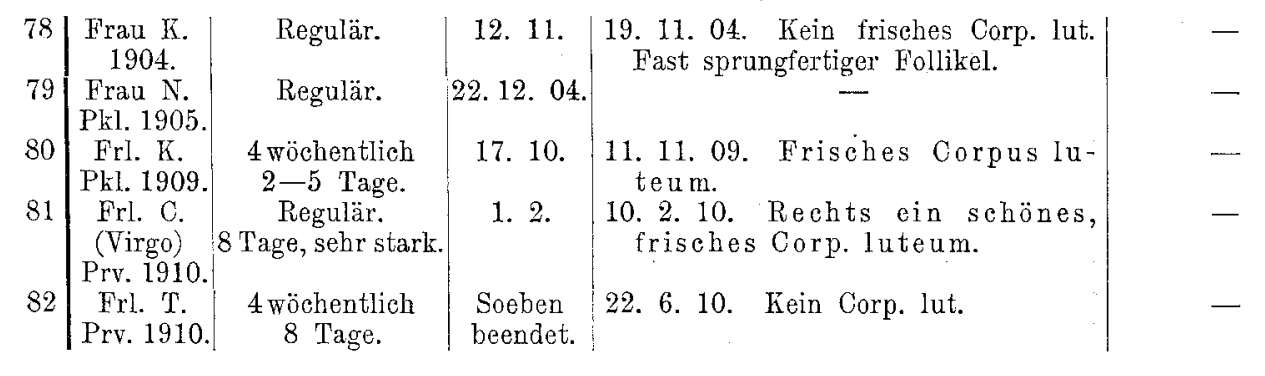

\section{Uterusexstirpation. b) bei Carcinom.}

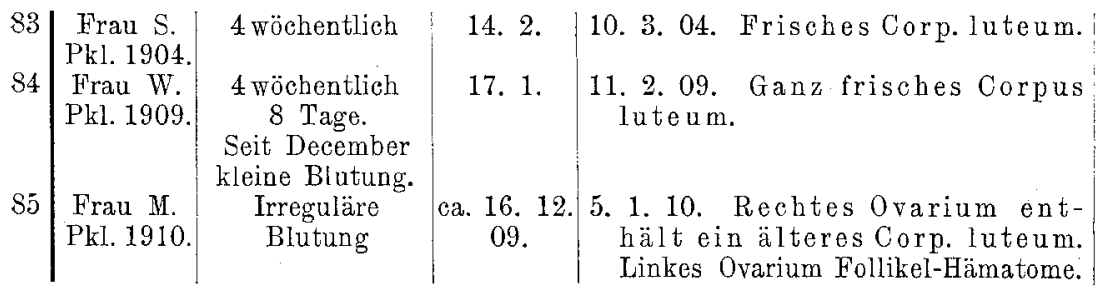

Kranke, die in der klinischen Beabachtung noch nicht menstruirten, zur genauen Berichterstattung über Eintritt und Verlauf der ersten Menstruation post operationem aufzufordern. Ein kleiner Theil hatte auch im Anschluss an die Operation sanguinolente Abflüsse, der uns und die Patientinnen verhinderte, die nächste Menstruation zu erkennen.

Frische Corpora lutea sind 20 mal notiert, alle Franen befinden sich zwischen dem 13.-27. Tage nach der letzten Menstruation, keine dieser Franen menstruiert z. $Z$. der Operation; die nächste Regel trat in 1-12 Tagen ein. Es handelte sich um regelmässig menstruirte Frauen; bei der Mehrzahl von ihnen trat die der Operation folgende Periode ausnahmsweise verfrüht ein, zweifellos unter dem allgemein bekannten Einflusse der Operation, zu dem im concreten Falle die Visitation und Betastung des Eierstockes dazukam. Bei 6 Patientinnen fehlen Notizen überdenEintritt der nächstfolgenden Menstruation, während die vorangegangene bei den 20 Fällen auf die Gesammtzahl der Tage berechnet vor 19 Tagen eingetreten 
746 L. Fraenkel, Neue Experimente zar Function des Corpus luteum.

ist. Ich gebe im folgenden eine Uebersicht der 20 Fälle, bei denen durch die Operation ein ganz frisches Corp. lut. constatirt wurde ${ }^{1}$ ).

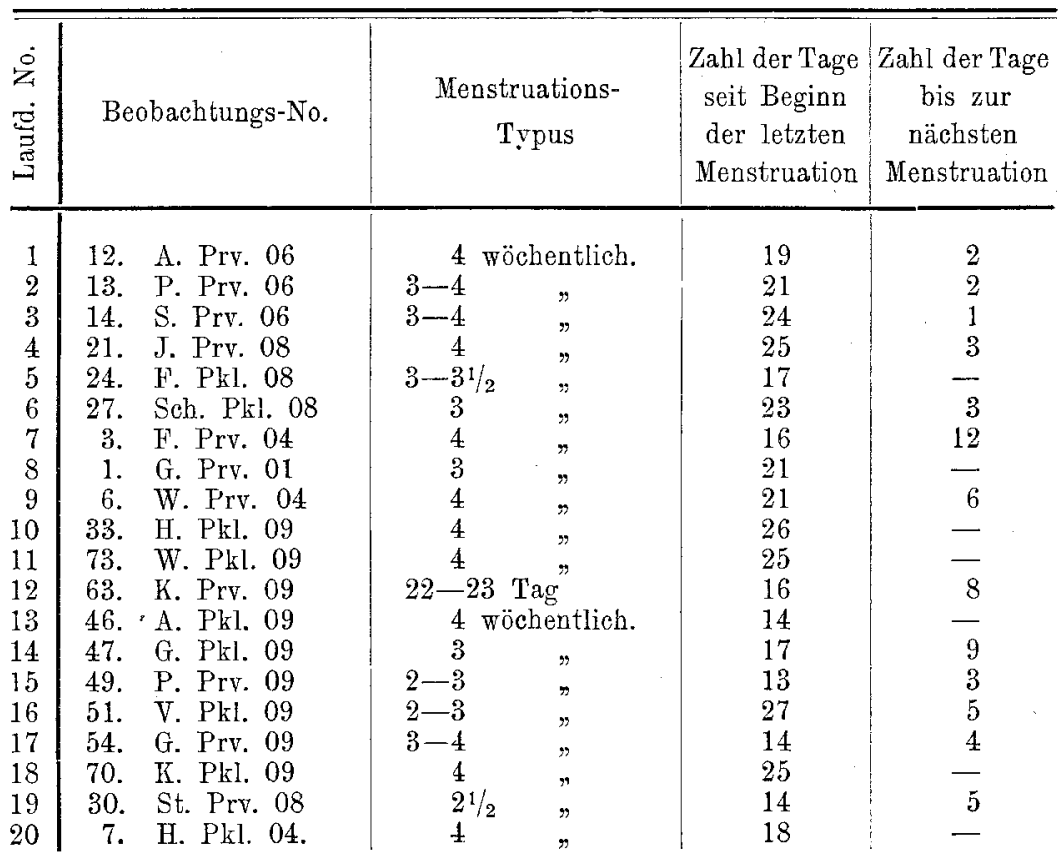

10 Frauen No. 2, 17, 22, 32, 37, 39, 40, 50, 57, 65, wurden während dicht vor resp. am Ende der Menstruation operirt; bei keiner war ein Corpus luteum zu sehen, die Ovarien klein und platt.

Aus diesen 30 Fällen, an die sich die übrigen mit seltenen Ausnahmen ${ }^{2}$ ) entsprechend anreihen, muss jch schliessen, dass durchschnittlich ca. 19 Tage nach Beginn der Menstruation ein Follikel platzt, etwa 8 Tage später der gelbe Körper auf der Höhe seiner Entwicklung steht, mit Beginn der neuen Menstruation sich zurück-

1) Wo Angabe über die nächste Periode fehlt, war die betr. Blutung nicht sicher von menstruellem Typus.

2) Im 38. 46. 56. Falle fand sich wider Erwarten kein Corpus luteum. Die sonst ganz reguläre Menstruation trat zum erwarteten Termin nicht ein, sondern 17 Tage bezw. 2 Monate später. Besonders bemerkenswerth sind noeh folgende Fälle: No. 1. Menstruation regulär. Die 2 prominentesten Follikel werden gesprengt. 2 Monate bleibt die Regel aus. - No. 5. Menstruation regulär. Das Corpus luteum wird zerdrückt. Nächste Regel nach 7 Wochen. 
bildet und am Ende der Menstruation verschwunden ist. Diese Annahme wird von allen beweiskräftigen Fällen gleichmässig bestätigt und zeigte nur diejenigen individuellen Schwankungen, die man bei den Generationsphasen niemals vermisst. Selbstverständlich documentiren sich alle Abweichungen vom 4wöchentlichen Menstruationstypus bei der Bildung des Corpus luteum im accelerierenden oder retardirenden Sinn.

Zu ganz dem gleichen Resultat kommt Villemin in seiner grossen, oben erwähnten Arbeit. Aus 39 Bauchschnitten, bei denen allerdings nicht angegeben ist, weshalb sie vorgenommen wurden, folgert der Verfasser, dass der Follikel 12-14 Tage vor dem Beginn der Menstruation springt. Während und nach der Regel fand V. niemals ein ganz frisches Corpus luteum. In den 15 Tagen, welche dem Beginn der Menstruation folgen, findet sich ein reifender Follikel und ein regressives Corpus Iuteum.

Mit den Resultaten von Leopold scheinen dagegen Untersuchungen im Einklange zu stehen, welche bei Thieren gemacht worden sind; insbesondere hat Heape (22) ein grosses Material von Affen der alten Welt zu sammeln Gelegenheit gehabt und behauptet für die zwei Gattungen Macacus rhesus und Semnopithecus entellus als wichtigstes Resultat, dass Menstruation und Ovulation nicht nothwendig gleichzeitig eintreten, ja, dass Menstruation ablaufen kann ohne eine Spur von Orulation. Was die erste Behauptung betrifft, so deckt sie sich vollkommen mit meinen Beobachtungen am Menschen. Die beiden Sexualfunctionen treten nicht gleichzeitig auf, wie man früher fast durchgängı glaubte. Vielleicht ist in dieser neuen Erkenntnis der psychologische Factor zu sehen, wolcher manche Autoren veranlasste, nun einen Schritt weiter zu gehen und zu glauben, dass beide Phänomene demnach in keiner Beziehung stehen. Heape hat aber weiterhin bei seinen katarrhinen Affen Menstruationen beobachtet ohne jede Spur von Ovulation, und dazu ist folgendes zu sagen: Bei den von ihm untersuchten Thieren, wie bei der Mehrzahl aller Säuger werden Brunstperioden unterschieden von Zeiten, wo das Thier kein Geschlechtsverlangen hat, sich nicht begatten lässt und keine Jungen gebiert. Heape haben nun in Bezug auf Semnipithecus èntellus und Macacus rhesus, für die er speziell die zweite Behauptung aufstellt, nur Menstruationspräparate zur anatomischen Untersuchung vorgelegen, die aus den Nicht-Brunstperioden (no-breeding-times) stammen 
Während der Brunst ziehen sich die Thiere in das tiefste Dickicht der vorderindischen Dshungles zurück, sodass man ihrer nicht habhaft werden kann. Heape selbst schliesst mit den Worten: "Es ist sehr wohl möglich, dass während der Brunstzeit Ovulation und Menstruation als gewöhnliche Regel bestimmte Beziehungen zueinander haben." Diese Vermutung wird in hohem Grade bestätigt durch Beobachtungen, die Herwerden (23) bei einer anderen Affenfamilie Cercocebus cynomolgus, sowie bei Tarsius spectrum gemacht bat. Ihm lagen innere Genitalien menstruirender Thiere sowohl aus den Brunst- wie aus den Ruheperioden vor. Bei der ersteren Gruppe hat er stets Ovulation gefunden und bei dieser verlief die Menstruation auch histologisch im Uterus vollkommen anders, i. e. mit bedeutend stärkerer Schwellung der Schleimhaut und Blutabsonderung als in den Ruheperioden. Bei Tarsius fand er jeden ,oestrischen Cyklus" (mit Brunstperioden identiseh) von einer Orulation begleitet. Aus diesen Angaben erklärt sich meines Erachtens die Differenz mit dem Menschen. Wenn auch Heape und einige seiner Anhänger Brunst- und Fortpflanzungsperioden etwas gewaltsam auch beim Nenschen construieren wollen, so müssen wir unbedingt daran festhalten, dass das menschliche Weib zu jeder Zeit des Jahres in vollkommen gleicher Weise begattungs- und fortpflanzungsfähig ist. Wir kennen hier also nur die eine Art Menstruation, welehe auch beim Affen nie ohne Ovulation verlief. So dankenswert die Untersuchungen von menstruirenden Thieren sind, so dürfen sie jedenfalls zu verallgemeinernden Schlüssen dazu nicht benützt werden, wenn ihr Geschlechtsleben von dem menschlichen so erheblich abweicht. Immerhin geben auch diese Untersuchungen sehr interessante Perspectiven, indem sie uns den Unterschied zeigen zwischen der Sexualphysiologie der in Wildheit lebenden Thierarten und dem durch Jahrtausende vergewaltigtem Naturtrieb der Mensehen. Bei unseren domesticirten Thieren sehen wir vielfach erhebliche Variationen im Geschlechtsleben, gegenüber den in Freiheit lebenden Verwandten. Es ist sehr wohl möglich, dass primär auch beim Menschen östrische Cyklen und zwei Arten von Menstruationen vorkamen, und dass der Einfluss des Corpus luteum sich nur auf die ersteren Perioden bezieht. Vielleicht würde uns das Stadium der Sexualphysiologie der Anthropoiden weiterbringen.

Eine hierher gehörende, zunächst befremdende Beobachtung machte Marshall (24a) beim Frettchen. Er fand im Gegensatz zu 
den anderen daraufhin untersuchten Säugethieren am Beginn des östrischen Cyklus stets Ovulation, wenn Coitus stattgefunden hatte, sonst aber nicht. Aus seiner, anderer und eigener Beobachtung ${ }^{1}$ ) komme ich zu dem Eindruck, dass der Follikelsprung vielfach durch den Coitus begünstigt oder beschleunigt wird. Trotzdem können wir für das Weib die Auffassung, dass ohne Cohabitation keine Ovulation stattfinde, keineswegs acceptiren, weil bei Jungfrauen dieselben Befunde am Eierstock erhoben werden, wie bei der im Geschlechtsverkehr lebenden Frau ${ }^{2}$ ). (Es ist sehr wohl möglich, dass nicht der Act selber, sondern die sexuelle Annäherung der Geschlechter die Eier zur Reife bringt; während aber die letztere bei den Thieren nur zur Zeit der Brunst unter dem Einflusse gewisser Riechstoffe ete. stattfindet, sind in dieser Beziehung für den Menschen die Lebensbedingungen so verändert, dass auch virgines zum Theil unbewusst unter geschlechtlichen Eindrücken stehen.)

Wenn ich zum Schlusse dieses Capitels resumiren darf, wie ich auf Grund meiner Beobachtungen die periodische Uterus- und Ovarialthätigkeit beurtheile, so möchte ich sagen: Die innere Secretion des Ovariums ist bewiesen, seine Prävalenz gegenüber der Uterusthätigkeit desgleichen. Die Hauptfunction in Bezug auf die innere Secretion des Eierstockes ist an den gelben Rörper gebunden; dieser ist eine eyklisch in Abständen von 3-4 Wochen sich bildende Drüse, die im Allgemeinen 19 Tage nach Eintritt der Jetzten Menstruation entsteht. Die Schwangerschaftsveränderungen des Uterus sind unbedingt an die Bildung dieser Drüse gebunden und folgen ihr zeitlich einige Tage nach. Wir werden also nicht tehlgehen, wenn wir auch die völlig identischen (homologen und homochronen) prämenstruellen Veränderungen auf sie beziehen. Indessen ist es nicht unmöglich, dass einmal eine echte oder PseudoMenstruation ohne Follikelsprung verlaufen kann, oder dass eine Ovulation keine Menstruation zu Wege bringt. Es ist denkbar, dass die Wellenbewegung im weiblichen Organismus, welche in den Blutdruckveränderungen vor und wäbrend der Menstruation ihren deutlichsten Ausdruck findet, in so eingefahrenen Bahnen abläuft, dass sehr wohl die noch im Blute kreisenden Luteinstoffe, zu denen

1) Vergl. meine Arbeit in diesem Archiv. Bd. 68. S. 24.

2) Vergl. z. B. die Fälle No. 3, 44, 49, 54, 72, 80, 81 meiner Zusammenstellung. 
sich vicariirend die Secrete anderer Drüsen hinzugesellen (Langerhans'schen Inseln etc.), ausnahmsweise genügen können, um ohne frisches Corpus luteum eine Art Menstruation hervorzubringen. Wir kommen hier an die letzten, zweifellos noch nicht völlig aufgeklärten Fragen aus der Biologie und functionellen Zusammengehörigkeit des Systems der inneren Drüsen, die erst in den letzten Jahren in Bearbeitung genommen worden sind. Aber diese Erwägungen und die gelegentliche Unregelmässigkeit in den von uns als gesetzmässig supponirten Beziehungen zwischen Orulation und Menstruation dürfen uns nicht hindern, das was sichergestellt ist und unbeschadet kleiner Abweichungen immer wieder constatirt werden kann, festzuhalten und von einem bestimmten Einfluss des Corpus luteum auf die Menstruation zu sprechen, wenn auch im Lichte fortschreitender Erkenntniss diese Anschaung vielleicht auf eine allgemeinere Basis gestellt werden wird. Der Werth einer jeden Theorie ist bekanntlich hauptsächlich ihr heuristischer und liegt in der Anregung zu neuen Fragestellungen, und in der von ihrem Autor aufgestellten Form und Gestalt hat noch keine die Jahrtausende überstanden. Dass aber in der Corpus luteum-Theorie ein guter Kern liegt, dass sie der letzten Wahrheit mindestens sehr nahe kommt, und dass bis zur fortschreitenden Erkenntniss der sich spannenden Fäden wir gut thun werden, an ihr festzuhalten, das glaube ich als Resultat dieser jahrelangen, sine ira durchgeführten Studien behaupten zu dürfen.

\section{Die Wirkung der Corpus luteum-Extracte}

ist in den letzten Jahren von verschiedenen Forschern experimentell and klinisch studirt worden. Lebreton (28) bat 1899 als erster den gelben Körper therapeutisch verwendet, und zwar gegen erhebliche Schwangerschaftsbeschwerden: Hyperemesis, Kopfschmerzen, Sehstörungen u. a.; nach ihm schützen die specifischen Stoffe aus dem Corpus luteum diẹ Frauen vor dem Auftreten von Intoxicationen; solche kämen zu Stande, wenn das Corpus luteum zu schnell sich zurückbildet.

7 Jahre später haben Ferroni (43) und Lambert (37) nahezu gleichzeitig und unabhängig von einander die grosse Giftigkeit des Corpus luteum-Extractes, auf die Lichtwitz (5) und ich (1) aufmerksam machten, bestätigt. Ferroni hat gezeigt, dass das Corpus luteum alle anderen Gewebe, selbst Leber, Placenta, Thyreoida an Giftigkeit übertrifft und weit toxischer wirkt, als das luteinfreie 
Ovarium. Es beeinflusst den gesammten Stoffwechsel am stärksten von allen damit in Vergleich gezogenen Organextracten. Lambert hat zum ersten Male exacte pharmakologische Untersuchungen vorgenommen: Frische gelbe Körper von Kuh und Sau wurdon fein zertheilt mit physiologiseher Kochsalz- oder Ringer'scher Flüssigkeit aufgeschwemmt, nach 3--4 Stunden filtrirt, neutralisirt und nun zu Versuchen verwendet. Injectionen unter die Froschhaut erzeugt Lähmung der Extremitäten, Sistirung der Athmung, Verlangsamung des Herzsehlages, bei grosser Dosis Tod, sonst Wiederhersteliung. Der isolirte Froschmuskel zeigt eine Verringerung der nervösen, Erhaltenbleiben der muskulären Erregbarkeit. Tropft man Extract auf das freigelegte Froschherz, so entsteht Absehwächung der Systole und Verlangsamung des Herzschlages. Wird das Extract in schwacher Dosis der Ringer'schen Flüssigkeit beigemengt, welche man durch das isolirte Froschherz circuliren lässt, so bleibt das Herz für kurze Zeit in Diastole stehen, ist die Dosis stark, so bleibt es so lange stehen, bis neue Ringer'sche Flüssigkeit ohne Extract zugeführt wird. Den Warmblütern (Kaninchen) subcutan applicirt, ist das Extract ohne Wirkung. $3 \mathrm{~cm}$ intravenös verändern in wenigen Minuten den Athmungstypus, erzeugen heftige peristaltische Bewegungen der Eingeweide, Tetanus universalis, wie bei Strychninvergiftung, Tod. Die Section ergiebt blutige Flüssigkeit in den serösen Höhlen, Anschoppung von Leber, Lunge und Meningen. Arterielle Blutdruckbestimmungen, bei Beginn der Krämpfe vorgenonmen, ergeben Blutdrucksteigerungen, welcher bei Einspritzungen der tödtlichen Dosis nach kurzer Zeit die Senkung des Druckes folgt. Dies Phänomen kann man mit luteinlosem Ovarienextract nicht erzielen. Das Corpus luteum muss demnach unter die Drüsen mit innerer Secretion von stärkster Giftigkeit gerechnet werden.

Hallion (38) zeigt 1907, dass die intravenöse Injection von gelbem Körper eine Congestion zur Thyreoidea herbeiführt und zu gleicher Zeit eine Herabsetzung des allgemeinen arteriellen Druckes.

Villemin 1908 prüft in seiner oben angeführten Arbeit die Angaben Lambert's nach und bestätigt sie. Er findet bei Kaninchen und Hund eine sehr stark giftige und gefässerweiternde Wirkung des Extractes, bei der Section war ihm am auffallendsten das regelmässige Vorhandensein von blutiger Flüssigkeit im Abdomen. Er erinnert an die Beobachtungen von Fedoroff (29), Keiffer (30) und Charrin (31), wonach das Blut der Frau vor 
752 L. Fraenkel, Neue Experimente zur Function des Corpus luteum.

und während der Menstruation sehr stark gefässerweiternd, blutdruckherabsetzend und giftiger sich erweist als gewöhnlich und schliesst daraus, dass diese Veränderung der Blutbeschaffenheit von den Corpus luteum-Secreten herrührt.

Livon (48) hat das Lutein von Kuh und Schwein für das Meerschweinchen äusserst giftig gefunden, so dass $0,2-0,3 \mathrm{~g}$ davon pro Kilogramm Thier die letale Dosis darstellt. Der Tod tritt durch Asphyxie ein, vorhergehen Dyspnoe, Convulsionen, Herabsetzung der allgemeinen Empfindlichkeit, Lähmung ${ }^{1}$ ).

Endlich erwähne ich der Vollständigkeit halber noch einmal die Experimente von Rebaudi; er konnte die grossen Wirkungen, welche der Verlust des gelben Körpers auf die Langerhans'schen Zellinseln des Pankreas ausübt, durch Einspritzung von Corpus luteum-Extract theilweise paralysiren.

Soweit die Pharmakodynamik des Juteinextractes.

Meine eigenen Untersuchungen bewegen sich seit 1903 auf therapeutischem, seit 1905 gleichzeitig auf experimentellem Gebiete. Ueber die letzteren Beobachtungen (verschieden starke Reaction auf das Gift bei Kaninchen, Meerschwein, Ratte, Maus und Gans) und die Möglichkeit langsamer Immunisirung wurde an anderen Orten berichtet. Vor 7 Jahren habe ich ohne Kenntniss von Jiebreton's Versuchen das Corpus luteum therapeutisch zu verwenden begonnen. Wenn der gelbe Körper die den cyklischen Uterinfunctionen vorstehende innere Drüse ist, so besteht analog anderen opotherapeutischen Erfahrungen die Möglichkeit nützlicher Verwendung der Luteinextracte. Von vornherein sind Ueberlegungen am Platze, welche nach zwei Richtungen übertriebene Hoffnungen zurückdämmen müssen:

I. Wir sind auf Versuche mit thierischen gelben Körpern bei Menschen angewiesen, während Artgleichheit des Materials bessere Erfolge verspricht.

II. Wir können nie und nimmer hoffen, durch irgend eine therapeutische Application die Wirkung der Drüse selbst nachzuahmen.

Während die Drüsen mit innerer Secretion zur Zeit ihrer höchsten Activität voraussichtlich einen ununterbrochenen, reich-

1) Anmerkung bei der Correctur: Bielow (49) bestätigt gleichfalls die blutdruckherabsetzende und puIsverlangsamende Wirkung des Secretes der „Glandula lutea". 
lichen Strom von Secret direct in's Blut senden, müssen wir statt des abgesonderten Productes einen Extract des herausgeschnittenen und durch die Verarbeitung vielleicht veränderten Organs benutzen, appliciren es aus äusseren Gründen meist nicht in's Blat und immer nur in Intervallen und können daher in keiner Weise die Concentration, Stetigkeit und Wirksamkeit zu erzielen boffen, wie von der arbeitenden Drüse selbst. Mit solchen Ueberlegungen bin ich an die Herstellung von "Lutein" gegangen. Aus den getrockneten gelben Körpern der Kuh bereitet und in Tablettenform verwendet, konnte von einer eventuell zu vermuthenden Wirkung auf Dysmenorrhoe, Graviditätsbeschwerden damals nichts besonders Günstiges berichtet, dagegen ein deutlicher Einfluss auf die sogen. Ausfallserscheinungen bei künstlicher oder spontaner Klimax beobachtet werden. Von da ab habe ich die Wirksamkeit des Luteins weiter zu erforschen gesucht. Während bei Menstrualschmerzen, Unregelmässigkeit der Periode und den Graviditätstoxicosen an meinem Material regelmässige Erfolge nicht zu beobachten waren, habe ich gegen die vasomotorischen Störungen infolge fehlender oder verringerter Function der Eierstöcke im Ganzen fortdauernd gute Resultate zu verzeichnen. Seit meinen ersten Mittheilungen habe ich das Lutein bei weiteren 237 Frauen verwendet, darunter $162 \mathrm{mal}$ aus der Indication "Ausfallserseheinungen". Wie damals habe ich nach Möglichkeit Mischbilder mit nervösen Beschwerden ausgeschaltet und einer suggestiven Wirkung durch Antisuggestion zu begegnen versucht (ich wüsste nicht, ob das Mittel helfen würde, es sei neu und unerprobt). Ich liess, wie früher, den eventuellen Erfolg durch genaue Selbstbeobachtung der Frauen über Zahl und Qualität der Anfälle registriren (durcbschnittliche Zahl der Anfälle am Tag, ob und wie oft dadurch Nachts erweekt, Daner des Anfalles, ob mit oder ohne Schweissausbruch, Zittern in den Gliedern, Klopfen in den Schläfen etc.). Die Antworten wurden in drei Rubriken eingetheilt, guter, mittlerer, geringer oder gar kein Erfolg, wobei ich die Kranken dieses Urtheil selbst abgeben liess. 74 Frauen habe ich nach der Luteinverordnung nicht wiedergesehen. Bei den übrigen 96 liegen 48 pCt. gute und sehr gute, 43 pCt. mittlere und 9 pCt. geringe Erfolge oder Misserfolge vor. (Die Fälle sind mit allen Details in einer Tabelle eingeordnet, welche ich dem Leser ersparen zu sollen glaubte.) Das Yittel hat also zweifellos in einer nicht ganz unbeträehtlichen Anzahl von Fällen versagt, aber dennoch in 91 pCt. einen deutlichen bis grossen Er- 
754 L. Fraenkel, Neue Experimente zur Function des Corpus luteum.

folg zu verzeichnen gehabt. Ich nehme an, dass dieses Resultat demjenigen anderer Organtherapien in keiner Weise nachsteht, vermuthe, dass die Misserfolge sich'auf ungeeignete Indicationsstellung, ungenügende Fabrikation und Haltbarkeit des Präparates, sowic hauptsächlich auf die in der Einleitung orwähnten aprioristisehen Bedenken beziehen. Uebles habe ich nie gesehen. Ich glaube also, wie früher, nur jetzt auf Grund einer bedeutend grösseren Erfahrung, das "Lutein" als Mittel gegen Ausfallserscheinungen empfehlen zu sollen 1). Ich verordne 3-6 Tabletten täglich; nach dem Essen, weil mitunter sunst über leichte Indigestion geklagt wird.

Oftmals sind mir von Aerzten Fälle berichtet worden, in denen das Lutein von eclatanter Wirkung war; auch fordern sich eine grosse Anzahl von Kranken spontan von Zeit zu Zeit Luteintabletten ein, welche sie einmal verordnet bekamen. Selbstverständlich ziehe ich alle diese Fälle nicht in das Bereich wissenschaftlicher Beobachtung, weil ich zu wenig über die Indication, wie über die genaue Art des Erfolges unterrichtet bin.

Ausser meinen eigenen Mittheilungen über die therapeutische Wirkung der Luteinextracte und den ganz kurzen von Bluhm (27), Keitler (51), Schauta (3), Birnbaum (7) und Kehrer (18) liegen aus neuerer Zeit zwei ausführlich mitgetheilte Pariser Untersuchungsserien vor:

Drevet (39) kommt in einer sehr sorgfältigen und kritischen Untersuchung, die mit durch Schwefelsäure und Glycerin extrahirten gelben Körpern in der Klinik Pozzi's angestellt wurde, zu ganz den. gleichen Resultaten wie ich. Die besten Erfolge gab ihm das Lutein gegen vasomotorische Ausfallserscheinungen: 10 glänzende Erfolge, 15 mal Besserung und 1 schlechtes Resultat. Alle übrigen Erscheinungsformen der Hypofunction der Ovarien (abnorme Blutungen, Schmerzen, nervöse und intestinale Symptome) wurden weniger zuverlässig beeinflusst.

Godart (40) hat mit dem Extract bei ovarieller Insufficienz im Hôpital Beaujon gearbeitet und gleichfalls bemerkenswerthe

1) Das Präparat wird weiter von der Hygiea-Apotheke in Breslau hergestellt. Ich überwache nach Möglichkeit die Fabrication, weil ich mich am Erfolge wissenschaftlich interessirt fühle. In weitergehender Verbindung stehe ich mit dem Vertriebe nicht, und habe mir nur ausbedungen, dass jede Art Reklame unterbleibt, so lange ich das Mittel ausprobe. 
Resultate, besonders gegen die amenorrhoischen Wallungen, „à type adipeux", zu erzielen geglaubt.

Weitere wissenschaftliche Untersuchungen über dic Wirksamkeit des Corpus luteum-Präparates sollen nach zwei Richtungen vorgenommen werden. Es soll bei derselben (intelligenten und objectiv sich beobachtenden) ausfallskranken Frau

I. der Vergleich in der Wirkung von Lutein mit ad hoc hergestelitem luteinlosem Oophorin,

II. der Vergleich in der Wirkung von Corpus luteum verschiedener Thiere gemacht werden, um zu sehen, welches für das menschliche den besten Ersatz bietet. - Lutein von der lebenden Frau dürfte zu selten gewonnen werden (Castration, Myomoperation, beim Porro, Uterusruptur, Extrauteringravidität, Bumm'scher Radicaloperation wegen Phthise), um es therapeutisch in grösserem Maassstabe zu verwenden.

\section{Ueber Gegenkörper}

gegen Ovarium und Corpus luteum habe ich an anderen Stellen berichtet. Diese Versuche sind noch nicht so weit gediehen, um von einer physiologischen oder therapeutischen Wirkung sprechen zu können, obwohl ausser mir und Lichtwitz (5) noch andere Autoren, wie Skrobansky (4), Miller (6), Birnbaum (7) sich mit der biochemischen Seite der Frage beschäftigt haben. Es lag nahe, an Stelle der experimentellen Ausschaltung der gelben Körper durch Application des Gegensecretes die Wirkung der Corpus luteumDrüse zu studiren. Hier möchte ich betonen, dass durch die Vorbehandlung eines Thieres mit unserem Organpräparat zwar im Blut ein Antikörper auftritt, der stark luteolytische Wirkung besitzt (welche notabene das Normalserum in unseren selbstverständlich ausgeführten Controlversuchen nicht aufwies), es scheint aber nicht, dass ein so (bei der Ziege z. B. mittels Kubovarium von mir) erzielter Antikörper functionelle Gegenwirkungen entfaltet. Die theoretischen Grundlagen sind auf dem Gebiet der Biochemie der Blutdrüsen bisher nicht geschaffen. Nach meinen Beobachtungen, über die später in extenso berichtet werden soll, muss ich annehmen, dass functionelle Gegenkörper gegen normale Secrete im Blut der Thiere nicht auftreten, denen man artfremdes Secret oder Drüsenextract selbst einspritzt. Für Gifte kann man experimentell auf diesem Wege Gegengifte erzeugen, gegen Zellen kann man immunisiren, 
also auch gegen unsere Corpus luteum-Zellen, anscheinend aber nicht gegen physiologische Secrete.

Wenn es wirkliche Gegen- und Ausfallskrankheiten giebt, d. h. solche, die durch Ueber- oder Unterfunction einer Drüse mit innerer Secretion entstehen, so ist $m$. E. die entgegengesetzte Wirkung des Blutes nicht in biochemischen Gegenkörpern zu suchen, die mit dem ersten Stoff sich binden und ihn neutralisiren, sondern in chemisch völlig fremden, functionellen. Solche können nicht im Blut eines anderen Organismus durch Ueberladung mit dem fraglichen Secret erzeugt werden, sondern sie entstehen spontan durch vermehrtes Ueberwiegen oder Neubildung des Secretes einer anderen Drüse. Beispielsweise kann ein "Anti-Lutein" nicht im strömenden Blute experimentell erzeugt werden, sondern bildet sich in einer anderen Drüse mit innerer Secretion, die dem Corpus luteum antagonistisch wirkt. Welche, wissen wir bis heute freilich noch nicht sicher - die Hypophysis gilt z. B. als eine von ihnen. Ich ziehe gern das Beispiel von der Osteomalacie heran, weil sie die ausgesprochene Gegenkrankheit zu den Ausfallserscheinungen ist, wie die therapeutischen Erfahrungen beweisen. Zweifellos muss die Osteomalacie mit der Ovarialthätigkeit in irgend einem Zusammenhang stehen, und ein schädigendes Plus von Ovarialsecret vorliegen. Beweis: Günstige Wirkung der Castration. Ausfallserscheinungen bestehen in einem schädlichen Minus. Beweis: Erzeugung derselben durch Castration. Nun nehme ich mit Wahrscheinlichkeit an, dass das Blut der Osteomalacie-Kranken einen Gegenkörper gegen Ausfallserscheinungen führt, wie das Blut der Ausfallskranken gegen die Knochenerweichung. Ich vermuthe aber, dass dies kein chemisehes Anti-Oophorin ist, sondern das Secret einer anderen Blutdrüse, die nun das Uebergewicht bekommt. Das könnte bei der Osteomalacie die Nebenniere sein, mit deren Extract gelegentlich Bossi u. a. prompte Wirkungen erzielten. (Dass hier der Erfolg kein zuverlässiger ist, darf bei der unklaren, schwankenden Beziehung der Drüsen zu einander nicht verwundern). Bis wir aber die genaue Wirkung der Drüsensecrete anfeinander kennen, ist die Hoffnung der Herstellung exact wirkender Gegenstoffe sehr gering; wahrscheinlich wird nicht das Secret einer einzelnen allein in Frage kommen, sondern vermuthlich bestimmte Mischungen mehrerer, wenn nicht aller. Damit freilich dürfte die Lösung der Frage weit entfernt sein, und der Gedanke an eine medicamentöse Verhütung oder Unterbrechung der Schwangerschaft 
mit Hilfe von Luteingegenstoffen noch gänzlich illusorisch. Dagegen sind therapeutische Bestrebungen, die eine Krankheit durch das Serum der andern zu heilen, sehr wohl am Platz. Ich verwende z. B. bei Osteomalacie das Blutserum von Kranken mit ovariellen Ausfallserscheinungen und vice versa. Selbstverständlich sind derartige Versuche in den ersten Kinderschuhen, für die das Gleiche gilt, was ich in der Einleitung zum vorigen Kapitel sagte: Die Blutdrüsen sind chemische Laboratorien, welche dauernd die gewünschten Stoffe in der nothwendigen Menge an die richtige Stelle sofort abgeben, und unsere Versuche roh-empirische Bemühungen, diese mit grosser Präzision arbeitenden Werkstätten durch Application von vielleicht ganz ungeeigneten Mischungen, die in willkürlichen Zeitabständen eingeführt werden, zu beeinflussen. Da kann auf einen sofortigen grossen Erfolg nicht gerechnet werden; vielleicht haben wir in der experimentellen Parabiose ein Mittel, um dieses Problem wenigstens im Thierversuch einer Lösung zu nähern.

Mit diesem Capitel bin ich am Ende meiner Mittheilungen über die Function des Corpus luteum angelangt. Bei der Beschäftigung mit diesen Fragen darf ich wohl verlangen, dass der streng bewiesene Hauptinhalt dieser Arbeit vollkommen getrennt wird von der Beurtheilung dieser letzten Hypothesen und vielleicht zukunftsreichen, z. Z. jedoch noch unbeweisbaren Ausführungen, die ich zur Ersehöpfung des Themas nicht ganz unterdrücken zu dürfen glaubte. Denn darüber darf kein Missverständniss aufkommen: Durch eine grosse Zahl von Experimenten am Thier, die völlig eindentig ausgefallen sind, wurde für dieses wenigstens die Function des Corpus lutenm klar bewiesen. Die Resultate unterscheiden sich von denen meiner ersten vor 7 Jahren veröffentlichten Arbeit wenig. Ich habe nur jetzt neue sehr grosse Versuchsserien beigebracht um die letzten Einwände zu widerlegen und dem Gesetz die allgemeine Geltung zu verschaffen. Die Ausführung so zahlreicher Experimente erforderte bei der nicht leichten Beschaffung geeigneter Thiere längere Zeit. So erklärt es sich, warum ich mehrere Jahre lang in dieser Sache geschwiegen habe. Wenn Birnbaum am Ende eines grossen Sammelreferates über diese Frage es als auffallend bezeichnet, dass es in den letzten Jahren recht still über die Corpus luteum-Theorie von beiden Seiten, Anhängern wie Gegnern, geworden sei, so ist für meinen Theil hiermit die Deutung dieser Thatsache gegeben. Im Uebrigen 
758 L. Fraenkel, Neue Experimente zur Function des Corpus luteum.

habe ich in dieser Arbeit ausser meinen eigenen Experimenten eine Uebersicht über die neue Literatur der andern Völker gebracht. Aus ihr ist zu ersehen, e intensiv und erfolgreich an dem weiteren Ausbau unserer Kenntnisse in den Beziehungen von gelben Körpern und Uterus einerseits, Gesammtorganismus andererseits, gearbeitet wird. Dies geschieht fast durchgehend fussend auf meinen Arbeiten, im Sinne Born's und meiner Lehre, die mittels alter und neuer Methoden nachgeprüft und durchaus bestätigt wird. Ich hoffe, dass diese Arbeit beitragen wird, auch in Deutschland dem Gesetze allgemeine Geltung zu verschaffen und neve Untersuchungen anzuregen.

\section{Lit e r a tur.}

1. L. Fränkel, a) Die Function des Corpus luteum. Dieses Archiv. Bd.68. - b) Weitere Mittheilung über die Function des Corp. lut. Verhandl. d. geb.-gyn. Ges. in Wien. Centralbl. f. Gyn. 1904. No. 19 u. 20. c) Orarialantikörper und Osteomalacie. Münch. Wochenschr, 1908. No. 25.

2. Halban, Discussion zu obigem Vortrag.

3. Schauta, Discussion zu obigem Vortrag.

4. Skrobansky, a) Discussion za obigem Vortrag. b) Beitrag zur Immunisirung mit Eierstock. Münch. med. Wochenschr. 1903. No. 44.

5. Mandl, a) Discussion zu obigem Vortrag. - b) Beitrag zur Kenntniss der Function der weiblichen Keimdrüse. Festschr. f. Chrobak. 1903.

5. Lichtwitz, Ueber Immunisirung mit Corpus luteum. Verhandl. d. med. Sect. d. schles. Ges. f. vaterl. Cultur. Breslau 1904.

6. Miller, Ueber Complementbindung bei Immunisirung mit Corpus luteum. Centralbl. f. Bakteriol. 1908. Bd. 46.

7. Birnbaum, Ovarien und innere Secretion. Zeitschr. f. allgem. Physiol. 1908. Bd. 8.

8. Kleinhans u. Schenk, Experimentelles zur Frage äber die Function des Corpus luteum. Zeitschr. f. Geburtsh. u. Gyn. 1908. Bd. 61.

9. Magnus, Ovariets betydning for svangerskabet med saerligt hensyn til corpus luteum. Norsk Magazin for Laegevidenskaben. 62. Jabrg. 1901.

10. Sauerbruch u. Heyde, Ueber Parabiose lünstlich vereinigter Warmblüter. Münch. med. Wochenschr. 1908. No. 4.

11. Specht, Mikroskopische Befunde am röntgenisirten Kaninchenovarium. Dieses Archiv. Bd. 78.

12. Lane Claypton and Starling, Proced. of the Roy. society. Vol. 77. p. 515.

13. Essen-Möller, Doppelseitige Ovariotomie im Anfang der Schwanger* schaft. Ausgetragenes Kind. Centralbl. f. Gyn. 1904. No. 28.

14. Gellhorn, Menstruation oline Ovarien. Centralbl. f. Gyn. 1907. No. 10. 
15. Lindenthal, Menstruation und Corpus luteum. Wiener klin. Wochenschr. 1903. No. 11.

16. Füth, Ueber Menstrur 'nnsverhältnisse bei einseitiger Ovarialgeschwulst. Med. Klinik. 1908. No. 8.

17. Campbell, Pathological ondition of the ovaries as a possible factor in the etiology of uterine fibroide. Journ. of obst. and gyn. Brit. Empire. Giugno 1905.

18. Kehrer, E.; Discussion zum Vortrage von Miller: Die Rückbildung des Corpus luteum. Münch, med. Wochenschr. 1910. No. 10.

19. Nyhoff, Zur excentrischen Hypertrophie des Uterus in der Schwangerschaft. Gyn. Sect. Vers. deutsch. Naturf. u. Aerzte. 1908.

20. Leopold u. Ravano, Neuer Beitrag zur Lehre von der Menstruation und Ovulation. Dieses Archiv. Bd. 83.

21. Hergesell, Das zeitliche Verhalten der Ovulation zur Menstruation. Inaug.Diss. Leipzig 1906.

22. Heape, 1) The mensu jon of Semnopithecus entellus. Phil. Transactions. 1894. Vol. 185. - 2) The menstruation and ovulation of Macacus rhesus. Lond. Phil. Transactions. 1897. Vol. 188. - 3) The sexual season of mammals and the relation of the "Pro-Oestrum " to menstruation. Quart. Journ. of micr. science. Vol. 44.

23. Herwerden, Beitrag zur Kenntniss des menstruellen Cyklus. Monatssehr. f. Geburtsh. Bd. 24.

24a) Marsha1l, The oestrous cycle in the common ferret. Quart. Journ. of micr. science. 1904.

b) Marshall and Jolly, Results of removal and transplantation of ovaries. Transact, of the Roy. soc. of Edinburgh. 1907. Vol. 45.

25. Hitschmann u. Adler, Der Bau der Uterusschleimhaut des geschlechtsreifen Weibes mit besonderer Berücksichtigung der Meustruation. Monatsschrift f. Geburtsh. 1908. Bd. 29.

26. Bucura, Nachweis von chromaffinem Gewebe und wirklichen Ganglienzellen im Ovarium. Wiener klin. Wochenschr. XX. Jahrg. 1907. No. 23.

27. Bluhm, Ueber einen Fall von Castration wegen Molimina menstrualia nach Hysterectomie. Monatsschr. f. Geburtsh. u. Gyn. Bd. XIX.

28. Lebreton, Corps jaune et auto-intoxication gravidique. Compt. rend. de la soc. de biol. 1907.

29. Fedoroff, Fonction utéro-ovarienne et leurs rapports avec les phónomènes de la menstruation et de la ménopause. Soc. des méd. russes de la soc. de Varsovie in Wratsch. 1897.

30. Keiffer, La menstruation dans ses rapports avec la pathologie générale. Gaz. gynécologique. 1900.

31. Charrin, Poisons des tissus. Paris 1907.

32. Sirtori, Sul contegno delle isole del Langerhans in gravidanza o in puerperio. Annali di ostetricia e ginecologia. 29. Jahrg. Bd. 1.

33. Ancel et Bouin, a) Sur la fontion du corps jaune. Action du corps jaune vrai sur l'utérus. Ibid. T. LXVI. - b) Action du corps jaune vrai sur la glande mammaire. Ibid. T. LXVI. - c) Sur les homologies et la signification des glandes à sérétion interne de l'ovaire. Ibid. T. LXVI. - d) Sur les homologies et la signification des glandes à sécrétion interne 
de l'ovaire. IIième note. Ibid. T. LXVI. - e) Sur la fonction du corps jaune. Première note de préliminaire. Méthodes de recherches. Extrait des compt. rend. des séanc. de la soc. de biol. T. LXVII. - f) Recherches sur les fonctions du corps jaune gestatif. I. Sur le déterminisme de la préparation de l'utérus à la fixation de l'oeuf. Journ. de physiol. et de pathol. générale. 1910. No. 1.

34. Niskoubina, Recherches sur la morphologie et la fonction du corps jaune de la grossesse. 1909.

35. Mulon, Parallèle entre le corps jaune et la cortico-surrénale chez le co. baye. Compt. rend. de la soc. de biol. 1906.

36. Jardry, La sécrétion interne de l'ovaire. (Synergie thyro-ovarienne.) Thèse des Paris. 1907.

37. Lambert, Sur l'action des extraits du corps jaune de l'ovaire. Compt. rend. de la soc. de biol. $190 \%$.

38. Hallion, Influence vaso-dilatatrice des produits ovariennes sur le corps thyroide. Compt. rend. de la soc, de biol. 1907.

39. Drevet, Effets thérapeutiques du corps janne de l'ovaire. Thèse de Paris. 1907.

40. Godart, Ménopause précoce et obésité. Thèse de Paris. 1908.

41. Villemin, Le corps jaune considéré comme glande à sécrétion interne de l'ovaire. Paris 1908.

42. Loeb, a) Ueber die künstliche Erzengung der Decidua und über die Bedeutung der Ovarien für die Deciduabildung. Centralbl. f. Physiol. 1908. Bd. 22. No. 16. - b) Die Erzeugung von Deciduen in dem Uteras des Kaninchens. Arch. f. Entwicklungsmechanik. Bd. 27. - c) Zur Analyse der Wachsthumsbedingungen des mütterlichen Theiles der Placenta beim Kaninchen. Ebenda.

43. Ferroni, a) Altre ricerche per la conoscenza della funzione del corpo luteo. Folia gynaec. Pavia. Vol. 1. Fasc.3. p.66. (Frommel. 1908.) - b) Sugli effetti delle injezioni sperimentali di estratto di corpo luteo. Annali di ostetrica e ginecologica. 29. Jahrg. 1907. Bd. I.

44. Fichera, Sulla ipertrofia della ghiandola pituitaria consecutiva alla castrazione. Policlinico. 1905.

45. Giorgi, Ovaia ed ipofisi e funzione del corpo luteo. La ginecologia. 1906.

46. Rebaudi, a) Ovaia, corpi lutei ed isoletti di Langerhans. La ginecologia moderna. I. Jahrg. 1908. - b) Eierstock-Corpus luteum und Iangerhans'scho Zellinseln. Centralbl. f. Gyn. 1908. No. 41.

47. Mulon, A propos de la fonction des corps jaunes chez le cobaye. Compt. rend. de soc. de biol. 1908. T. 64. 15. II.

48. Livon, Sur l'action des extraits du corps jaune de l'ovaire. Réunion biol. de Marseille. 1909. 16. III.

49. Bielow, Ueber die physiologische Bedeutung der Corpora lutea der Ovarien. Russky Wratsch. 1910. No. 12.

50. Regaud et Dubreuil, a) Corps jaune, menstruation et rut. Extrait du Lyon médical. Bd. CXII. - b) Existe-t-il des relations entre les phénomènes du rut et la présence des corps jaunes ovariens chez la lapine? Compt. rend. de la soc. de biol. 1. IJ. 08. - c) A propos des corps jaunes de la lapine. Ils n'out avec le rut aucune relation. Compt. rend. de la soc. 
L. Fraenlel, Neue Experimente zur Funetion des Corpus luteum. 761

de biol. 14. 1II. 08. - d) L'ovulation de la lapine n'et pus spontanée. Compt. rend. de la soc. de biol. 28. III. 08. - e) Observations nouvelles relatives à l'indépendance des corps jaunes et du rut chez la lapine. Compt. rend. de la soc. de biol. 4. IV. 08. - f) Action du mal sur le rut et l'ovulation chez la lapine. Compt. rend. de la soc. de biol. 28. XI. 08. - g) Influence du male sur les fonctions ovariennes. Extrait du Lyon médical. 2. VII. u. 19. XII. 08. - h) Sur les relations fonctionnelles des corps jaunes avec l'utérus non gravide. Extrait du nLyon médical". 11. IV. 09.

51. Keitler, Ueber das anatomische und funktionelle Verhalten der belassenen Ovarien nach Exstirpation des Uterus. Monatsschr. f. Geburtsh. u. Gyn, Bd. 20. 